\title{
Strategies to Improve the Stability of Perovskite-based Tandem Solar Cells
}

\author{
Wentao Zhou, Yihua Chen, Huanping Zhou * \\ Beijing Key Laboratory for Theory and Technology of Advanced Battery Materials, Key Laboratory of Polymer Chemistry and \\ Physics of Ministry of Education, BIC-ESAT, Department of Materials Science and Engineering, College of Engineering, Peking \\ University, Beijing 100871, China.
}

\begin{abstract}
Organic-inorganic metal halide perovskite-based tandem solar cells have attracted significant research attention in recent years. The power conversion efficiency of perovskite-based tandem can efficiently meet the requirements of practical applications; however, their instability limits their commercialization. The most commonly used wide-bandgap perovskites suitable for top sub-cells, which are based on $\mathrm{I} / \mathrm{Br}$ alloying at $\mathrm{X}$ site, often suffer from severe phase segregation. When exposed to light illumination, a smaller bandgap phase appears and acts as a carrier trap, leading to a reduction in the quasi-Fermi level splitting and large $V_{O C}$ deficit. The narrow-bandgap perovskites suitable for bottom sub-cells, which are based on $\mathrm{Sn} / \mathrm{Pb}$ alloying at B sites, always face atmospheric instability. When exposed to air,

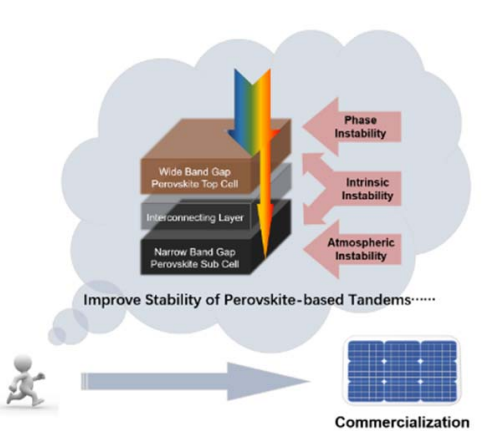
$\mathrm{Sn}^{2+}$ is rapidly oxidized to $\mathrm{Sn}^{4+}$, which can shorten the carrier diffusion length and result in a drop in efficiency. Herein, we summarize the recent advances in perovskite-based tandem solar cells from the viewpoint of stability. We analyzed the stability data of highly efficient perovskite-based tandems reported so far, such as perovskite/silicon, perovskite/perovskite, and perovskite/copper indium gallium selenide (CIGS) tandems. We found that the key to improve the perovskite-based tandems is to improve the stability of the perovskite sub-cells. Then, we systematically analyzed the phase and atmospheric instability of wide- and narrow-bandgap perovskite, respectively, providing some reasonable strategies to tackle the instability. Compositional engineering, crystallinity optimization, and employing other perovskites with wide bandgaps are effective means to avoid phase instability of the $\mathrm{l} / \mathrm{Br}$ alloying perovskite. Introducing the reducing additives, improving the film morphology, and forming a 2D/3D structure can help in improving the atmospheric stability of Sn-Pb narrow bandgap perovskites. Furthermore, we review the intrinsic instability of perovskite and corresponding improvement methods, which are inevitable in future tandem solar cells. By reducing the methylamine (MA) content in perovskite component and suppressing ion migration, the long-term operational stability is greatly enhanced. Finally, we briefly summarize the instability issues related to the interconnecting layer. In addition to the optimization of perovskite-based tandem devices, encapsulation also plays a crucial role in improving stability against environmental stressors. Studies based on improving the stability of perovskite-based tandems are still in the early stage. However, with a deeper understanding of the stability of perovskite sub-cells and the interconnecting layer, the commercialization of perovskite-based tandems, especially perovskite/silicon tandem devices, is promising to be achieved in the near future.
\end{abstract}

Key Words: Perovskite; Tandem solar cell; Stability; Wide bandgap; Narrow bandgap

\footnotetext{
Received: September 14, 2020; Revised: October 13, 2020; Accepted: October 24, 2020; Published online: November 2, 2020.

${ }^{*}$ Corresponding author. Email: happy_zhou@pku.edu.cn.

The project was supported by the National Natural Science Foundation of China $(51972004,51722201,51672008,91733301)$, the National Key Research and Development Program of China (2017YFA0206701), and the Natural Science Foundation of Beijing, China (4182026).

国家自然科学基金(51972004, 51722201, 51672008, 91733301), 国家重点研究发展计划项目(2017YFA0206701), 北京自然科学基金(4182026)资助
}

(C) Editorial office of Acta Physico-Chimica Sinica 


\title{
提升基于钻钛矿的叠层太阳能电池稳定性的策略
}

\author{
周文蹈, 陈怡华，周欢萍 ${ }^{*}$ \\ 北京大学工学院材料科学与工程系, 北京工程科学与新兴技术高精尖创新中心, 高分子化学与物理教育部重点实验室, \\ 北京先进电池材料理论与技术重点实验室, 北京 100871
}

\begin{abstract}
摘要: 近年来, 基于有机无机金属卤化物钽钠矿的叠层太阳能电池引起了巨大的研究热潮。但是, 不稳定性限制了其商 业化。适用于顶部子电池的宽带隙钻铁矿存在相不稳定性, 而适用于底部子电池的窄带隙钻钣矿存在空气不稳定性。首 先, 我们总结了提升基于钙铁矿的叠层太阳能电池稳定性的最新进展。然后, 我们系统地分析了导致宽带隙钻钛矿的相 不稳定性和窄带隙钙铁矿的空气不稳定性的原因, 并为解决这些不稳定性问题总结了合理的策略。我们也简短地总结了 中间层带来的不稳定性以及相应的解决措施。最后, 我们回顾了钻铁矿材料固有的本征不稳定性和相应的改进方法, 这 对于将来发展更稳定的叠层太阳能电池中是必要的。我们认为随着对钻铁矿子电池的理解越来越深入, 基于钙钋矿的叠 层电池特别是钻钦矿/硅叠层电池将会迅速商业化。
\end{abstract}

关键词: 钙铁矿; 叠层太阳能电池; 稳定性; 宽带隙; 窄带隙 中图分类号: 0649

\section{Introduction}

Solar cells collect sustainable and renewable solar radiation energy and convert it into electricity directly, which become potential alternatives for traditional fossil energy. In recent decades, photovoltaic technologies, mainly crystalline silicon solar cells, have experienced rapid development towards higher power conversion efficiency (PCE), lower manufacturing cost, and thus a gradually reduced levelized cost of electricity ${ }^{1}$. Nevertheless, photovoltaic (PV) technology only contributes a minor portion to the world electricity market share. Boosting the PCE of solar cells is indeed a dominant way to make PV more economically feasible.

According to Shockley-Queisser (S-Q) limit ${ }^{2}$, the maximum theoretical efficiency of a single-junction solar cell is about $33 \%$. Multi-junction (e.g. tandem) solar cells can further mitigate thermal energy losses by combining two or more absorbers with different bandgaps. For a typical two-junction solar cell device, it consists of a wide bandgap top sub-cell absorbing high-energy photons, and a narrow bandgap bottom sub-cell absorbing remaining low-energy photons, which ultimately reduce energy loss due to thermalization. Based on detailed balance limit theory ${ }^{3}$, tandem solar cells could promote the PCEs to much

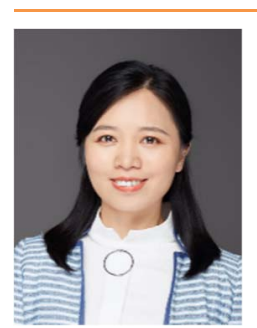

Huanping Zhou received her $\mathrm{PhD}$ degree in inorganic chemistry from the Peking University in 2010. After that, she joined University of California, Los Angeles, as a post-doctoral researcher from 2010 to 2015. From July 2015, she joined Peking University as an assistant professor in Department of Materials Science and Engineering, College of Engineering. She is a materials chemist with expertise in the fields of nanoscience, thin film optoelectronics, and the development of related devices, such as photovoltaic cells, LEDs, etc. Currently, her research lab is focused on thin film optoelectronics, e.g., perovskite materials and solar cells. higher level, depending on the number of absorbers employed. Currently, research efforts are focusing on increasing the number of active layers and optimizing them in desired ways. Specifically, tailoring their bandgaps and thicknesses with effective photon management ${ }^{4,5}$ have shown effects to minimize spectral loss ${ }^{6,7}$. In addition, other functional layers within the device are carefully engineered to further increase the performance of tandem device. All these attempts lead to the highest PCE of the multijunction device with a PCE up to $47.1 \%$ with a concentrator and $39.2 \%$ without concentrator ${ }^{8}$.

In recently years, organic-inorganic hybrid perovskite materials, with a typical $\mathrm{ABX}_{3}$ crystal structure, have attracted intensive attention when applied in thin-film solar cells due to its ideal optoelectronic properties, like high absorption coefficient and long carrier diffusion length. In this type perovskite, A site is usually occupied with $\mathrm{CH}_{3} \mathrm{NH}_{3}{ }^{+}\left(\mathrm{MA}^{+}\right), \mathrm{HC}\left(\mathrm{NH}_{2}\right)_{2}^{+}\left(\mathrm{FA}^{+}\right)$or $\mathrm{Cs}^{+}$; $\mathrm{B}$ site is usually $\mathrm{Pb}^{2+}$ or $\mathrm{Sn}^{2+} ; \mathrm{X}$ site is halide ion such as $\mathrm{I}^{-}$, $\mathrm{Br}^{-}$and $\mathrm{Cl}^{-}$. Currently, PCE of perovskite-based single junction solar cells has reached up to $25.5 \%$. Additionally, the ease of tuning its bandgap from 1.17 to $\sim 2.8 \mathrm{eV}$ via changing constituent components makes it suitable for absorbing layers in tandem solar cell ${ }^{9-11}$. On the bandgap regime of $\sim 1.7-2.8 \mathrm{eV}$, it can be achieved by partial substitution of $\mathrm{I}^{-}$with $\mathrm{Br}^{-}$at $\mathrm{X}$ site ${ }^{12}$ and/or replacing organic cations with inorganic cation $\mathrm{Cs}^{+}$at $\mathrm{A}$ site ${ }^{13}$. This makes perovskite suited for as absorbing layer in a wide bandgap top sub-cells to couple with other narrow bandgap absorber like silicon ${ }^{14}$, copper indium gallium selenide (CIGS) ${ }^{15}$ organic photovoltaics (OPV) ${ }^{16,17}$, and narrow bandgap perovskites as well.

Two-terminal (2T) and four-terminal (4T) configurations are currently the mainstream of perovskite-based tandem photovoltaic devices. In the $2 \mathrm{~T}$ configuration, the top sub-cell and bottom sub-cell are connected in series via an 
interconnecting layer, usually tunnel junction or recombination layer ${ }^{18}$. In the $4 \mathrm{~T}$ configuration, top sub-cells and bottom subcells can be fabricated and optimized independently. In the past few years, the performance of perovskite/silicon tandem solar cell is rapidly improved since the first demonstration by Bailie et al. ${ }^{19}$, which mainly benefits from the solid foundation of silicon photovoltaic technology and rapid development of perovskite. In 2018, Oxford PV 20 developed a $1 \mathrm{~cm}^{2}$ perovskite/silicon tandem device with certified efficiency of $28 \%$. It is the first time that a perovskite/silicon hybrid device has edged out the best silicon single-junction device. Recently, McGehee et al. ${ }^{21}$ reported a triple-halide perovskite with suppressed photoinduced phase segregation, which is combined with silicon bottom sub-cell achieving $27 \%$ efficiency in a twoterminal device. Although the great efficiency has been achieved by the perovskite-based tandem solar cells, the long-term stability issue still limited their further development.

Herein, we discussed and summarized progress and challenges on improving stability of perovskite-based tandem device, as illustrated in Fig. 1. First, we summarized recent progress of stability of perovskite-based tandems. We focused on highly efficient perovskite/silicon tandems and perovskite/ perovskite (all-perovskite) tandems reported in recent years, dedicated in reviewing their stability and corresponding test procedures, not the way to improve their efficiency. We then summarized the origin of critical instability problems of the perovskite sub-cells: phase instability of wide bandgap top subcell and atmospheric instability of narrow bandgap bottom subcell, and corresponding strategies to tackle them. What's more, we briefly discussed the general intrinsic instability of perovskite materials, which could bring additional instability issue for perovskite-based tandems. We also briefly summarized the instability issues related with interconnecting layer. At last, we provided our prospects for the future development of stable perovskite-based tandem solar cells.

\section{Recent advances in stability of perovskite- based tandem solar cells}

The key advantage of tandem solar cells is that they can theoretically achieve higher power conversion efficiency that single-junction cells cannot achieve. Recent research efforts are dedicated in improving efficiency of perovskite-based tandems in recent years through optical management, electrical loss reduction, etc. Although stability test for perovskite-based tandems is frequently conducted in most works that focus on improving efficiency, the study on improving stability of perovskite-based tandems are still in the early stage. Also, the progress on stability of perovskite-based tandems is lagging that of perovskite single-junction solar cells. In this section, we have summarized the recent advances of three mainstream perovskitebased tandem configurations: perovskite/silicon, perovskite/ perovskite and perovskite/CIGS tandem solar cells, with more attention on their stability assessment and improvement.

\subsection{Perovskite/silicon tandem solar cells}

Perovskite/silicon tandem solar cell is the most attractive research direction among perovskite-based tandems, and its stability is continuously improving in recent years by enhancing the stability of wide bandgap perovskite top sub-cells. McGehee et al. ${ }^{22}$ introduced a bilayer of $\mathrm{SnO}_{2}$ and zinc tin oxide (ZTO) as interconnecting layer in perovskite/silicon tandem, realizing certified efficiency of $23.6 \%$ with $1-\mathrm{cm}^{2}$ area (Fig. 2a-c). This method could effectively reduce parasitic absorption and improve carrier transport and also provide buffer function for wide bandgap $\mathrm{Cs}_{0.17} \mathrm{FA}_{0.83} \mathrm{~Pb}\left(\mathrm{Br}_{0.17} \mathrm{I}_{0.83}\right)_{3}$ perovskite. In addition, the dense and pin-hole free $\mathrm{SnO}_{2} / \mathrm{ZTO}$ bilayer was beneficial for improving stability of perovskite top sub-cell. The perovskite single-junction solar cell operated with minimal degradation in performance after ageing at maximum power point (MPP) for $1000 \mathrm{~h}$ without encapsulation. Then, perovskite sub-cells were encapsulated using sheets of glass with ethylene-vinyl acetate (EVA), by curing at a temperature of $140{ }^{\circ} \mathrm{C}$ for $20 \mathrm{~min}$. The butyl rubber edge seal was also used to prevent device from moisture. After encapsulation, the devices were subjected to the damp heat test, according to the International Electrotechnical Commission (IEC) design qualification testing protocol 61215 for 'Crystalline Silicon Terrestrial Photovoltaic (PV) Modules'. The perovskite devices passed damp heat test, which requires the performance of device drops within $10 \%$ in $1000 \mathrm{~h}$ when stored at $85{ }^{\circ} \mathrm{C}$ and $85 \%$ relative humidity. Recently, McGehee et al. ${ }^{21}$ alloyed chlorine $(\mathrm{Cl})$ into wide bandgap perovskite crystal lattice, achieving phase-stable triple halide $(\mathrm{I} / \mathrm{Br} / \mathrm{Cl})$ perovskite. This method can suppress the light-induced phase segregation and increase photocarrier lifetime, enabling efficiency of $27 \%$ in $1-\mathrm{cm}^{2}$ two-terminal perovskite/silicon tandem. The semitransparent top sub-cell utilized triple-halide perovskite as absorber exhibited $<4 \%$ efficiency degradation after $1000 \mathrm{~h}$ MPP tracking at near $60{ }^{\circ} \mathrm{C}$, as shown in Fig. 2d, e. Ballif et al. ${ }^{23}$ developed a deposition process that achieve the conformal growth of

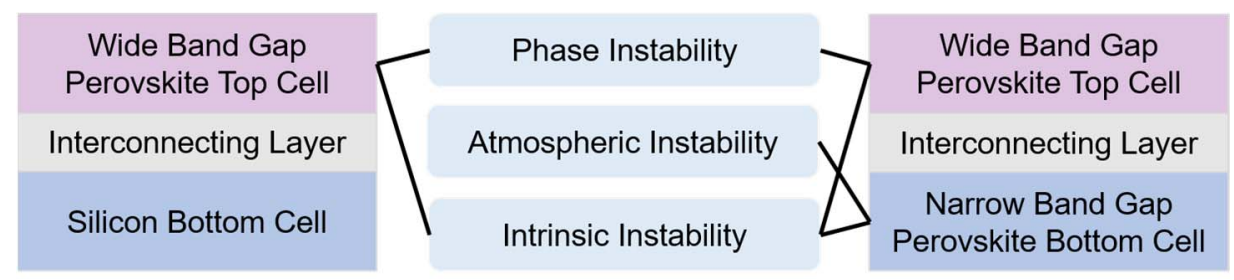

Fig. 1 A schematic illustration of instability issues of perovskite-based tandem solar cell

(Take perovskite/silicon and perovskite/perovskite tandems as examples). 


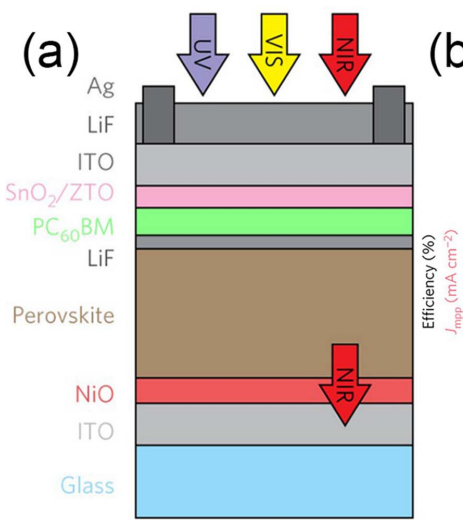

(b)

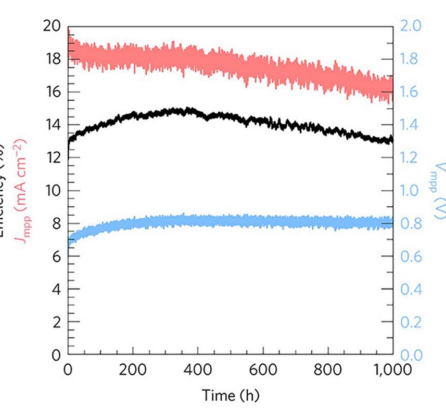

(c)

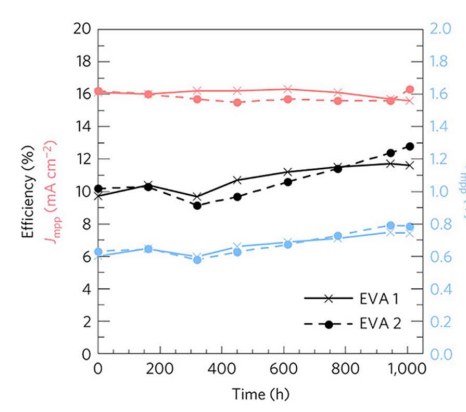

(d)

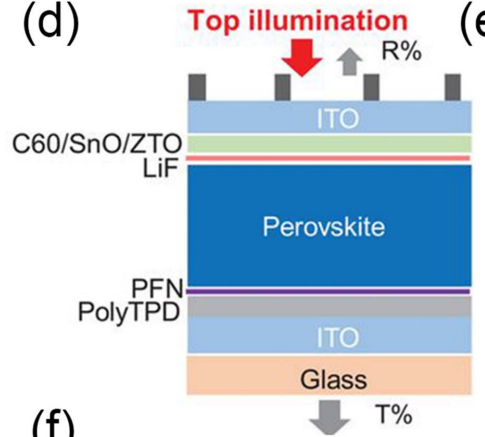

(e)

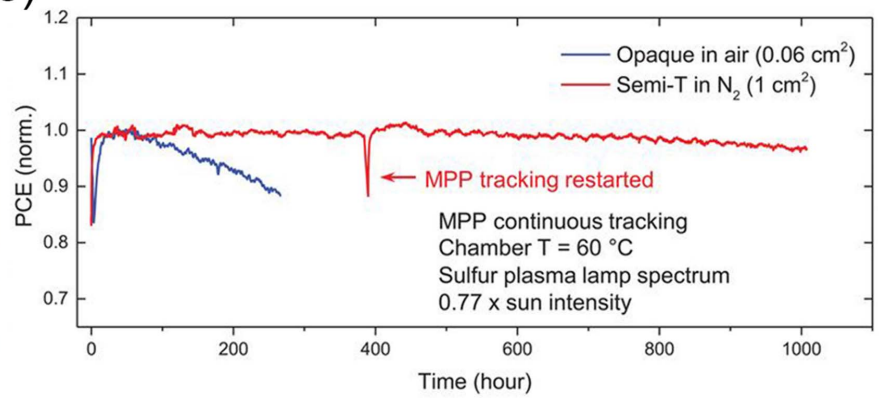

$(\mathrm{f})$

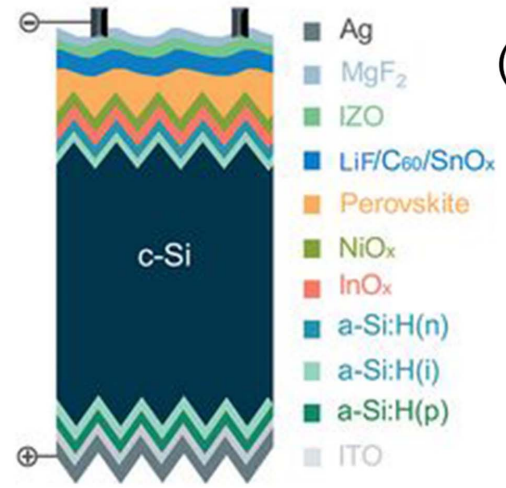

(g)

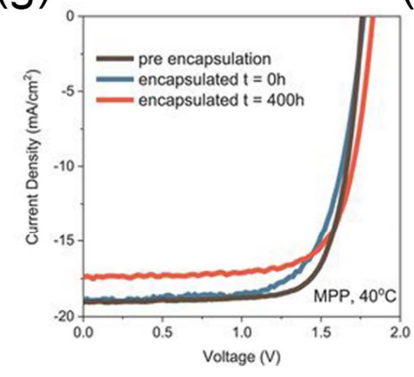

(h)

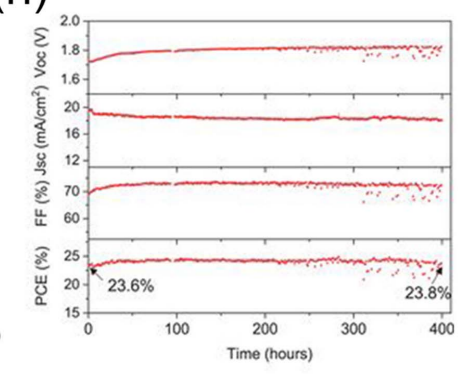

Fig. 2 (a) A schematic illustration of wide bandgap perovskite single-junctional semitransparent solar cell. (b) Efficiency (black), current density $\left(J_{M P P}\right.$, red) and voltage ( $V_{M P P}$, blue) of perovskite single-junction device with no encapsulation during $1000 \mathrm{~h}$ of continuous MPP tracking. (c) Efficiency (black), $J_{M P P}$ (red) and $V_{M P P}$ (blue) of encapsulated with EVA, glass, and a butyl rubber edge seal during damp heat testing. (d) A schematic illustration of top-illuminated semitransparent perovskite device. (e) Normalized PCE during MPP tracking under accelerated conditions ( $\left(0.77\right.$-sun illumination and $60^{\circ} \mathrm{C}$ ) of $1-\mathrm{cm}^{2}$ semitransparent (red, tested in $\mathrm{N}_{2}$, averaged from two devices in the same batch) and opaque devices (blue, tested in air with relative humidity of $\sim 30 \%$ ). (f) A schematic illustration of solution-processed perovskite/textured silicon tandem device. a-Si:H(n), n-doped hydrogenated amorphous silicon; a-Si:H(i), intrinsic hydrogenated amorphous silicon; a-Si:H(p), p-doped hydrogenated amorphous silicon. (g) $J-V$ curves of tandem device without encapsulation at the beginning and the end of the MPP tracking test.

(h) $J-V$ parameters measured over $>400 \mathrm{~h}$ of MPP tracking at $40{ }^{\circ} \mathrm{C}$.

(a, b, c) Adapted from reference ${ }^{22}$, Copyright 2017, Macmillan Publishers Limited. (d, e) Reproduced with permission ${ }^{21}$, Copyright 2020, American Association for the Advancement of Science. (f, g, h) Reproduced with permission ${ }^{25}$, Copyright 2020, American Association for the Advancement of Science.

perovskite top sub-cell on micrometer-sized pyramids of textured monocrystalline silicon. The combination of conformal perovskite top sub-cell with textured silicon sub-cell can improve the light harvesting, exhibiting efficiency of $25.2 \%$. The perovskite single-junction solar cell produced with the method presented in this work exhibited less than $10 \%$ efficiency loss after $1000 \mathrm{~h}$ damp heat tests at $85{ }^{\circ} \mathrm{C}$ and a $\mathrm{RH}$ of $85 \%$. Kim et al. ${ }^{24}$ introduced $\mathrm{PEA}\left(\mathrm{I}_{0.25} \mathrm{SCN}_{0.75}\right)$ as mixed anion additive in
$1.68 \mathrm{eV}$ bandgap perovskite, achieving a PCE of $20.7 \%$ in perovskite single-junction solar cell. They found that the addition of PEA( $\left.\mathrm{I}_{0.25} \mathrm{SCN}_{0.75}\right)$ could result in the formation of $\mathrm{PbI}_{2}$-based 2D phase located at surface and grain boundary. The wide bandgap perovskite solar cell with additive exhibited impressive light stability, which can remain $80 \%$ of initial efficiency after $1000 \mathrm{~h}$ of continuous illumination without capsulation. 
The operational stability test for tandem devices is undoubtedly stricter than that of wide bandgap perovskite top sub-cells. Relatively less research work have reported the stability of the whole tandem device. In the work by Ballif et al. ${ }^{23}$, operational stability for perovskite/silicon tandem device at MPP conditions under continuous AM 1.5G illumination without any ultraviolet-blocking filter was conducted. The tandem device can retain MPP output efficiency of $22 \%$ after 61 h. Sargent et al. ${ }^{25}$ combined solution-processed perovskite top sub-cells with fully textured silicon heterojunction bottom subcells, realizing certified efficiency of $25.7 \%$ for perovskite silicon tandem. The highly efficient tandem device also exhibited impressive operational stability. The tandem devices encapsulated using glass and polyolefin encapsulate (POE) retained their original efficiency after ageing at MPP for $400 \mathrm{~h}$, as shown in Fig. $2 \mathrm{f}-\mathrm{h}$. The operational stability test was set at $40{ }^{\circ} \mathrm{C}$ and $\sim 40 \%$ to $50 \%$ relative humidity using 1 -sunequivalent illumination. The authors attributed this excellent stability to the replacement of organic hole transport layer with inorganic $\mathrm{NiO}_{x}$. Huang et al. ${ }^{14}$ developed a blade-coating method for conformal deposition of hole transport layer and planarizing perovskite layer on textured silicon sub-cell. The unencapsulated perovskite/silicon tandem device remained 92\% of its initial efficiency after constant illumination for $100 \mathrm{~h}$ in ambient atmosphere.

\subsection{Perovskite/perovskite tandem solar cells}

Improving stability of narrow bandgap perovskite sub-cell is crucial for perovskite/perovskite tandem solar cell. Alloying $\mathrm{Sn}$ and $\mathrm{Pb}$ at $\mathrm{B}$ site of perovskite is the commonly used method to achieve bandgap suited for bottom perovskite sub-cell. The facile oxidation of $\mathrm{Sn}^{2+}$ is the major obstacle for $\mathrm{Sn}-\mathrm{Pb}$ perovskite, which will be discussed in detail later in this review. By optimizing the narrow bandgap perovskite sub-cell, stability of all-perovskite tandem is gradually improved. Yan et al. ${ }^{26}$ incorporated $\mathrm{PbCl}_{2}$ as additive to enlarge the grain size and reduce the electronic disorder of $\mathrm{Sn}-\mathrm{Pb}$ perovskite. The $2 \mathrm{~T}$ allperovskite tandem was constructed by combining $1.75 \mathrm{eV}$ perovskite top sub-cell with $2.5 \% \mathrm{Cl}$-incorporated $1.25 \mathrm{eV}$ perovskite bottom sub-cell. The tandem device could retain $85 \%$ of its initial efficiency after MPP tracking in air for $80 \mathrm{~h}$. The $V_{\mathrm{OC}}$ of tandem device remained steady under a continuous 1 sun illumination for over $200 \mathrm{~s}$. In addition, an encapsulated tandem device retained $94 \%$ of its initial efficiency after storage in ambient air for 45 days. Later in 2019, Yan et al. ${ }^{27}$ found that the addition of guanidinium thiocyanate (GuaSCN) in $\mathrm{Sn}-\mathrm{Pb}$ perovskite can improve the efficiency and stability of $\mathrm{Sn}-\mathrm{Pb}$ perovskite sub-cell and corresponding all-perovskite tandem device, as shown in Fig. 3a, b. Introducing GuaSCN can result in the formation of 2D structure at grain boundaries, reducing defects states in grains and grain boundary/surface regions. The operational stability tests were conducted for $1.25 \mathrm{eV}$ narrow bandgap perovskite and corresponding $4 \mathrm{~T}$ and $2 \mathrm{~T}$ tandem device. The narrow bandgap bottom sub-cell was encapsulated with cover glass and ultraviolet-curable epoxy before testing. It showed approximately a linear degradation over time at the first 115 h of MPP tracking: $\sim 0.09 \%$ per hour; and $\sim 0.05 \%$ per hour for the $4 \mathrm{~T}$ tandem device. The $2 \mathrm{~T}$ device can retain more than $88 \%$ of initial efficiency after $100 \mathrm{~h}$ of continuous MPP tracking. Huang et al. ${ }^{28}$ added cadmium ions $\left(\mathrm{Cd}^{2+}\right)$ in $\mathrm{Sn}-\mathrm{Pb}$ perovskite precursor. The addition of $\mathrm{Cd}^{2+}$ can de-dope narrow bandgap $\mathrm{Sn}$ $\mathrm{Pb}$ perovskite and reduce electron trap density, which play a positive role in improving stability of corresponding $2 \mathrm{~T}$ monolithic all-perovskite tandem device. The tandem device can maintain $91.8 \%$ of their initial efficiency under 1 sun illuminetion for $200 \mathrm{~h}$. Tan et al. ${ }^{29}$ introduced metallic Sn powder in Sn$\mathrm{Pb}$ perovskite precursor and optimize interconnecting layer, achieving the highest efficiency of $2 \mathrm{~T}$ all-perovskite tandem device reported so far. The tandem solar cell also exhibited promising operational stability, maintaining $90 \%$ of their initial efficiency after $463 \mathrm{~h}$ of MPP tracking under full 1-sun illumination, as shown in Fig. 3c, d. Recently, Tan et al. ${ }^{30}$ found that introducing bulky organic cation phenethylammonium (PEA) to passivate $\mathrm{Sn}-\mathrm{Pb}$ perovskite is beneficial for improving operational stability of perovskite bottom sub-cell. The PEApassivated $\mathrm{Sn}-\mathrm{Pb}$ perovskite exhibited $\mathrm{T}_{90}$ (the time at which PCE degrades to $90 \%$ of the initial value) of $8.6 \mathrm{~h}$. The corresponding $2 \mathrm{~T}$ tandem device retained $95 \%$ of their efficiency after $65 \mathrm{~h}$ of operation at MPP point.

Optimizing interconnection layer in 2T tandem device is also helpful to ensure both high efficiency and stability. Huang et al. ${ }^{31}$ demonstrated a simplified interconnection layer only composed of $\mathrm{C}_{60}$ and $\mathrm{SnO}_{2-x}$, ensuring the high efficiency and photostability of $2 \mathrm{~T}$ all-perovskite tandem under illumination. Compared to a complicated interconnection layer (ICL) in most existing all-perovskite tandems, the simplified interconnection structure $\mathrm{C}_{60} / \mathrm{SnO}_{2-x}$ can reduce the sputtering process damage for underlying functional layers and improve stability of tandem device (Fig. 3e). The 2T tandem device was constructed by combining $1.78 \mathrm{eV}$ perovskite $\mathrm{Cs} 0.4 \mathrm{FA}_{0.6} \mathrm{PbI}_{1.95} \mathrm{Br}_{1.05}$ with 1.21 $\mathrm{eV}$ perovskite $\mathrm{Cs}_{0.05} \mathrm{MA}_{0.45} \mathrm{FA}_{0.5} \mathrm{~Pb}_{0.5} \mathrm{Sn}_{0.5} \mathrm{I}_{3}$. The tandem device remained $94 \%$ of initial efficiency under 1-sun illumination after $1000 \mathrm{~h}$, as shown in Fig. 3f. The improved stability could be attributed to multiple factors: more $\mathrm{Cs}$ in $1.78 \mathrm{eV}$ perovskite for suppressed phase segregation; less $\mathrm{Sn}$ in $1.21 \mathrm{eV}$ perovskite for suppressed oxidation; more stable buffer layer $\mathrm{SnO}_{1.76}$ compared to poly (3,4-ethylenedioxythiophene)-poly(styrenesulfonate) (PEDOT:PSS) for bottom sub-cell. The phase instability of wide bandgap perovskite and atmospheric instability of narrow bandgap perovskite will be discussed later.

\subsection{Perovskite/CIGS tandem solar cells}

Perovskite and CIGS photoactive materials both possess tunable bandgaps, which provides the potential of combining two sub-cells into a tandem solar cell with respectable efficiency. In recent years, through optimization of the perovskite sub-cells, stability of perovskite/CIGS solar cells has been gradually improved. Yang et al. ${ }^{32}$ deposited a transparent metal oxide layer 
(a)

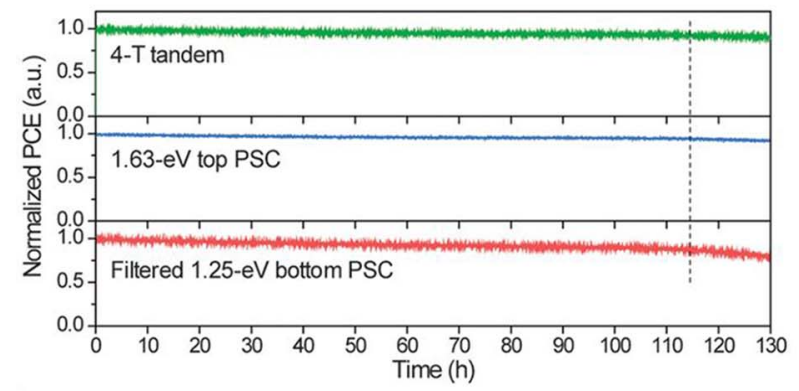

(b)

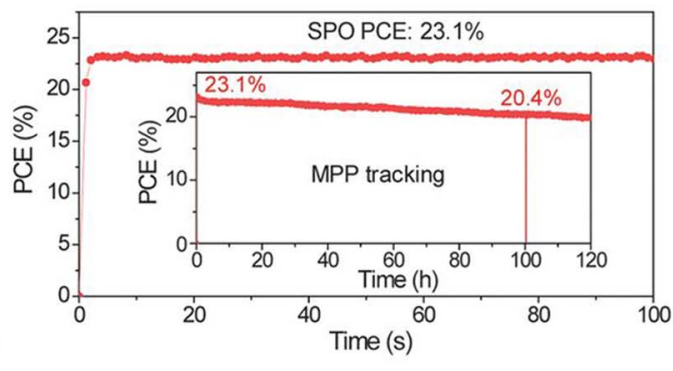

(c)

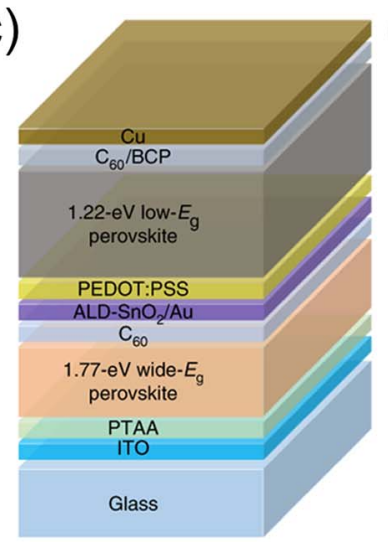

(e)

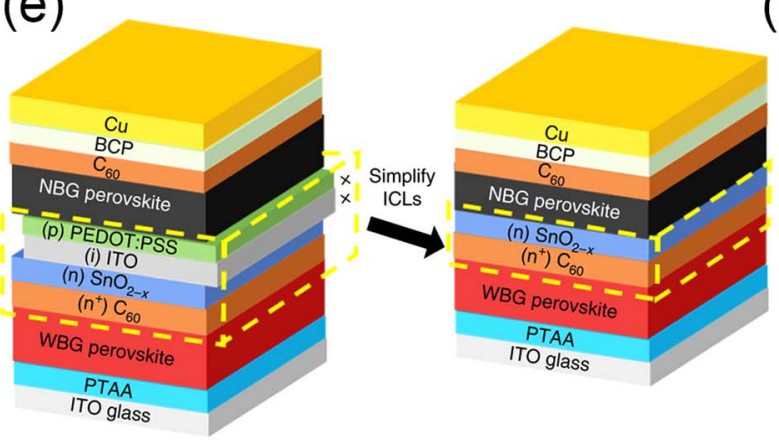

(d)

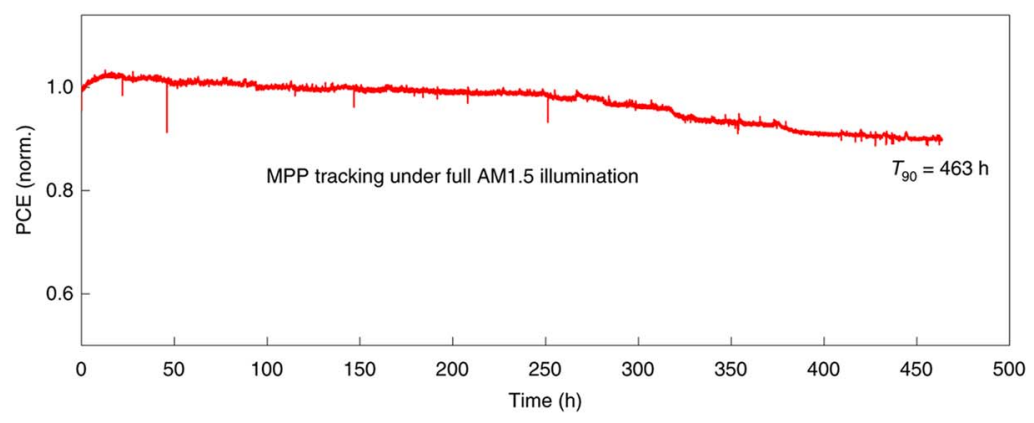

(f)

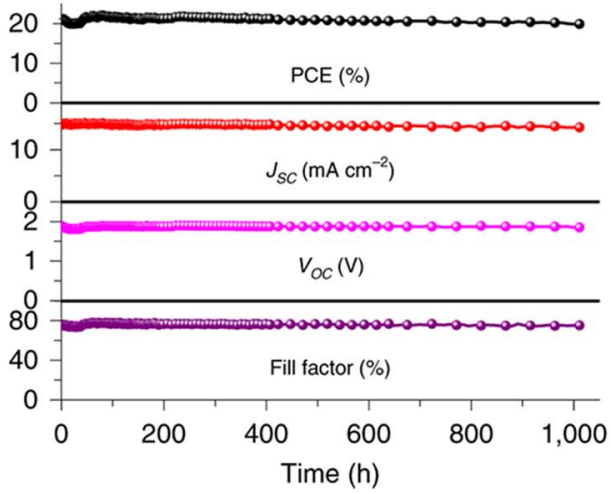

Fig. 3 (a) MPP tracking of wide bandgap top perovskite sub-cell, the filtered bottom sub-cell, and 4T tandem device under simulated AM 1.5G one-sun illumination. (b) SPO efficiency and MPP tracking (inset) of the $2 \mathrm{~T}$ tandem cell under one-sun illumination. (c) A schematic illustration of monolithic $2 \mathrm{~T}$ all-perovskite device. (d) MPP tracking of $2 \mathrm{~T}$ tandem device under full AM 1.5G illumination. (e) A schematic illustration of tandem

devices based on typical structured ICLs of $\mathrm{C}_{60} / \mathrm{SnO}_{2-x} / \mathrm{ITO} / \mathrm{PEDOT}$ :PSS and simplified ICLs of $\mathrm{C}_{60} / \mathrm{SnO}_{2-x}$ (BCP, bathocuproine; PTAA, poly[bis(4-phenyl)(2,4,6-trimethylphenyl)amine]). (f) Long-term photostability of tandem device based on $\mathrm{C}_{60} / \mathrm{SnO}_{1.76} \mathrm{ICLs}$ measured under continuous simulated AM1.5G illumination for $1000 \mathrm{~h}$ at room temperature.

(a, b) Reproduced with permission from reference ${ }^{27}$, Copyright 2019, American Association for the Advancement of Science. (c, d) Adapted from reference ${ }^{29}$, Copyright 2019, Macmillan Publishers Limited. (e, f) Adapted from reference ${ }^{31}$, Copyright 2020, Macmillan Publishers Limited.

composed of zinc oxide $(\mathrm{ZnO})$ nanoparticles and indium tin oxide (ITO) on the top of perovskite/CIGS tandem device, allowing for sufficient light transmission while improving operational stability. They proposed that the deposited metal oxide layer is dense to be resistant against moisture. The unencapsulated perovskite/CIGS tandem device remained $>$ $88 \%$ of its initial efficiency (started with $22.0 \%$ efficiency) after $500 \mathrm{~h}$ of continuous MPP tracking at $30{ }^{\circ} \mathrm{C}$ ambient environment. Amran et al. ${ }^{33}$ replaced poly[bis(4-phenyl)(2,4,6- trimethylphenyl)amine] (PTAA), a hole transport layer in perovskite top sub-cell, with self-assembled monolayers (SAM) based on carbazole bodies with phosphonic acid anchoring groups. They argued that SAM layer could provide a stronger hole-selectivity and can be conformally deposited on rough surface of the as-deposited CIGSe bottom sub-cell. The SAMbased perovskite single single-junction perovskite device showed better operational stability under MPP tracking at simulated 1 sun. The time evolving $V_{\mathrm{OC}}$ of single-junction 
perovskite device was also tracking at open-circuit condition under light soaking at 1 sun illumination. SAM-based device rendered virtually stable $V_{\mathrm{OC}}$, while $V_{\mathrm{OC}}$ of PTAA-based device showed substantial drop after $2 \mathrm{~h}$. It is inferred that SAM was chemically robust with virtually no volume, which could avoid structural damage caused by ion migration from perovskite to the SAM/perovskite interface.

\section{Phase instability of wide bandgap perovskite}

As discussed above, tandem solar cells usually consist of two sub-cells with different but suitable bandgaps. This allows tandems to mitigate energy losses compared to single-junctional device and have potential to exceed S-Q efficiency limit. The partial replacement of constituent components at $\mathrm{X}$ sites in perovskite absorber from $\mathrm{I}^{-}$to $\mathrm{Br}^{-} / \mathrm{Cl}^{-}$will bring about an enlargement in the bandgap, which have been widely investigated in numerous literatures 9,34-36. However, the common wide bandgap perovskite absorber, which based on the $\mathrm{I} / \mathrm{Br}$ component, often suffers from the severe phase segregation and followed huge $V_{\mathrm{OC}}$ deficit, limiting the commercial development of perovskite-based tandem solar cells. In this section, we discussed the origin of phase instability in wide bandgap perovskite, and comprehensively reviewed the possible improvement strategies, including compositional engineering, crystallinity optimization and employing other perovskite with wide bandgap.

\subsection{Phase segregation and underlying mechanism}

Alloying iodide and bromide at X site makes wide bandgap perovskite vulnerable in phase stability, reflecting in the serious phase segregation under illumination ${ }^{36,37}$. Hoke et al. ${ }^{38}$ firstly observed the light-induced phase segregation in $\mathrm{MAPb}\left(\mathrm{I}_{1-x} \mathrm{Br}_{x}\right)_{3}$ (Fig. 4a-c), which could cause the formation of smaller bandgap phase acting as traps. The smaller bandgap phase was consistent with the iodine-rich phase. Photoinduced carriers will be trapped into low bandgap phase, leading to the reduction in quasi-Fermi (a)

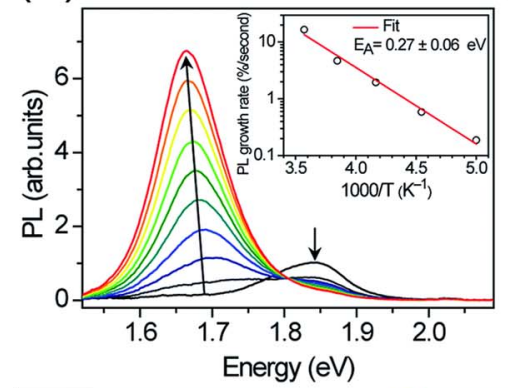

(b)

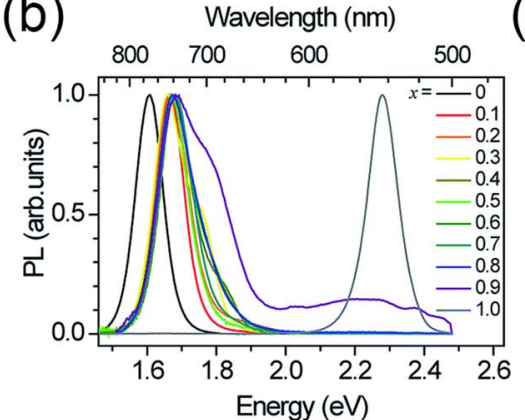

(c)

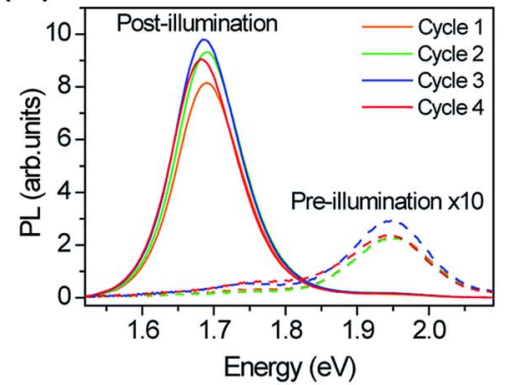

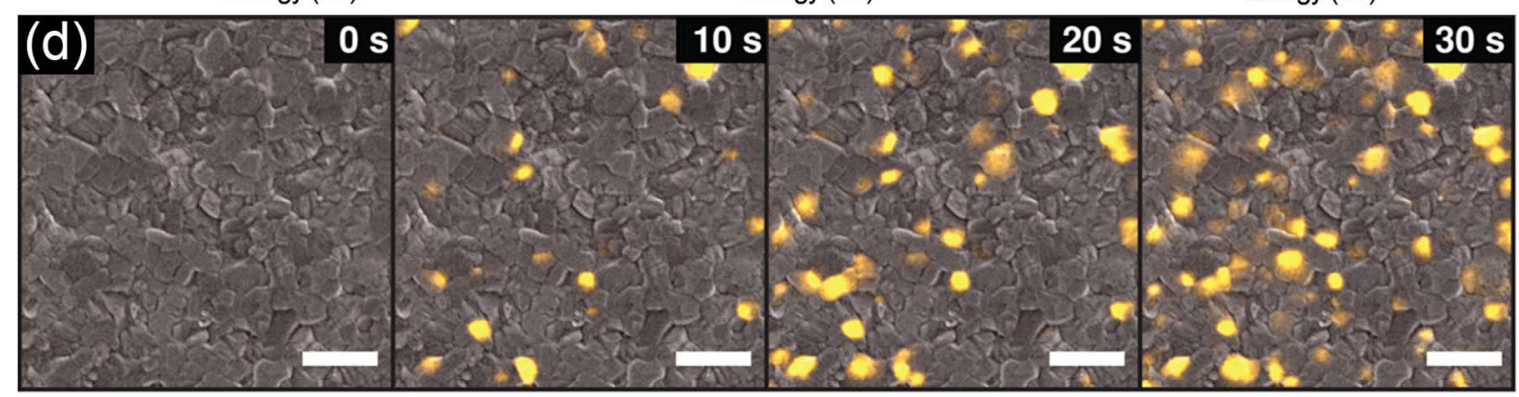

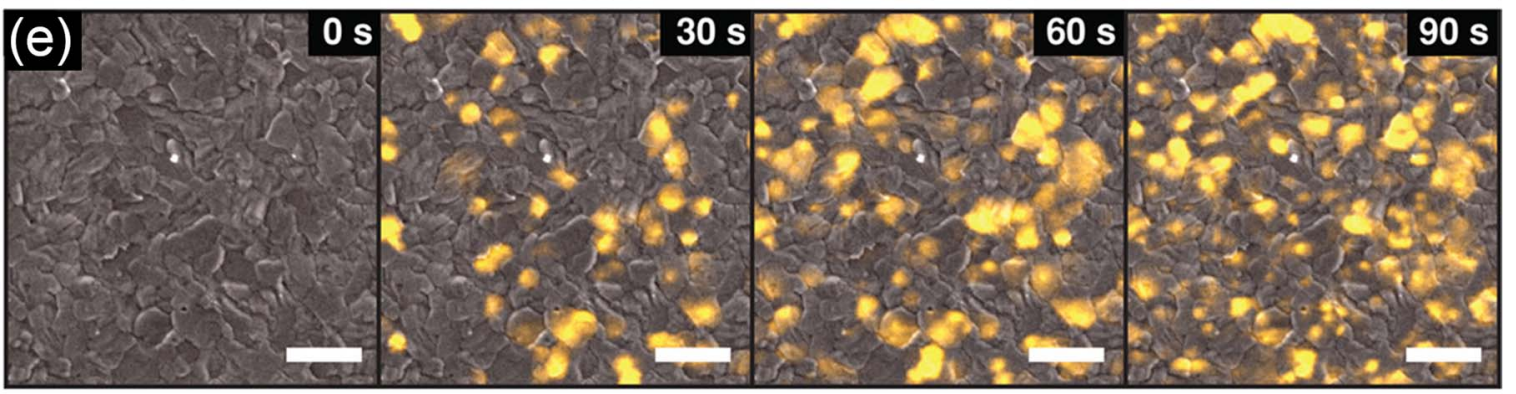

Fig. 4 (a) PL spectra of an $\operatorname{MAPb}\left(B_{x} \mathrm{I}_{1-x}\right)_{3}, x=0.4$ perovskite film over $45 \mathrm{~s}$ in $5 \mathrm{~s}$ increments under $457 \mathrm{~nm}, 15 \mathrm{~mW} \cdot \mathrm{cm}^{-2}$ light at $300 \mathrm{~K}$. Inset: temperature dependence of initial PL growth rate. (b) Normalized PL spectra of MAPb( $\left.\operatorname{Br}_{x} \mathrm{I}_{1-x}\right)_{3}$ perovskite films after illuminating for 5-10 min with 10-100 $\mathrm{mW} \cdot \mathrm{cm}^{-2}, 457 \mathrm{~nm}$ light. (c) PL spectra of $x=0.6$ perovskite film after sequential cycles of illumination for 2 min $\left(457 \mathrm{~nm}, 15 \mathrm{~mW} \cdot \mathrm{cm}^{-2}\right)$ followed by $5 \mathrm{~min}$ in the dark. (d, e) Duty cycle for CL image series for perovskite film. The scale bars are $2 \mu \mathrm{m}$. (a, b, c) Reproduced with permission from reference ${ }^{38}$, Copyright 2015 , Royal Society of Chemistry. (d, e) Reproduced with permission from reference ${ }^{41}$, 
level splitting and large $V_{\mathrm{OC}}$ deficit. Phase segregation phenomenon in mixed halide perovskite, also called "Hoke effect", was subsequently confirmed by other groups ${ }^{39}$. The mechanism behind phase segregation has attracted intensive research interests. Brivio et al. ${ }^{40}$ carried out density functional theory (DFT) simulation to understand thermodynamic origin of light-induced instability of $\mathrm{MAPb}\left(\mathrm{I}_{1-x} \mathrm{Br}_{x}\right)_{3}$. They calculated the thermodynamic total energy and entropy of the mixing composition and built the phase diagram based on the calculated Helmholtz free energy. They suggested that the phase diagram could explain the miscibility gap at $300 \mathrm{~K}$. Bischak et al. ${ }^{41}$ employed cathodoluminescence (CL) imaging combined with molecular simulations to understand the dynamics of halide phase segregation, as shown in Fig. 4d-e. It was observed that photoinduced electron-hole pairs would rapidly dissociate and create free electrons and holes, which can deform the surrounding lattice via electron-phonon coupling. Local strain caused by the spatial overlap between the deformed lattice and a single-charge density could result in local phase segregation. This finding suggests that the substantial photoinduced carriers play an important role on phase instability of mixed halide perovskite. In addition, Barker et al. ${ }^{42}$ believed that halide defects act as low-energy migration pathways for halide ions and promote halide segregation. Halide migration process is driven by the internal gradient of photoinduced carrier generation rate via strain gradient in lattice.

\subsection{Compositional engineering}

Compositional engineering is a simple but effective method to improve the phase stability of wide bandgap perovskite. Snaith et al. ${ }^{43}$ demonstrated the photostable mixed halide perovskite $\mathrm{FA}_{0.83} \mathrm{Css}_{0.17} \mathrm{~Pb}\left(\mathrm{I}_{0.6} \mathrm{Br}_{0.4}\right)_{3}$ with $1.74 \mathrm{eV}$ bandgap via partially replacing $\mathrm{FA}^{+}$with $\mathrm{Cs}^{+}$in thermally stable $\mathrm{FAPbI}_{3}$ perovskite. As shown in Fig. 5a, the composition-optimized perovskite showed no significant red shift in photoluminescence (PL) emission after light exposure, which indicated an enhanced phase stability compared to $\mathrm{MAPb}\left(\mathrm{I}_{1-x} \mathrm{Br}_{x}\right)_{3}$ reported by Hoke and coworkers ${ }^{38}$. The semitransparent solar cell using $\mathrm{FA}_{0.83} \mathrm{Cs}_{0.17} \mathrm{~Pb}\left(\mathrm{I}_{0.6} \mathrm{Br}_{0.4}\right)_{3}$ as absorber delivered stabilized power output of $12.5 \%$. Duong et al. ${ }^{44}$ have shown that employing four cations ( $\mathrm{Rb}, \mathrm{Cs}, \mathrm{FA}$ and $\mathrm{MA}$ ) in perovskite is beneficial for improving photostability. Perovskite with quadruple cation exhibited $95 \%$ efficiency after $12 \mathrm{~h}$ of continuous one-sun illumination. It is worth noting that this report investigated the cell performance under working condition instead of the red shift in PL emission which has milder illumination intensity. McGehee et al. ${ }^{45}$ believed that raising Cs fraction is beneficial for reducing the reliance on incorporating high fraction of $\mathrm{Br}$ to obtain bandgap required for top sub-cell. The reduced $\mathrm{Br}$ fraction results in better resistance against halide segregation. As shown in Fig. 5b, $1.68 \mathrm{eV}(25 \mathrm{Cs} / 20 \mathrm{Br})$ and $1.75 \mathrm{eV}(40 \mathrm{Cs} / 30 \mathrm{Br})$ bandgap perovskites with more $\mathrm{Cs}$ and lower $\mathrm{Br}$ only showed slightly peak shift in PL measurement after excitation. Recently, McGehee et al. ${ }^{23}$ incorporated $\mathrm{MAPbCl}_{3}$ in crystal lattice to achieve stable triple-halide perovskite (I, $\mathrm{Br}, \mathrm{Cl})$. Different from other reports using $\mathrm{MACl}$ or $\mathrm{PbCl}_{2}$ as additive ${ }^{46,47}$, they found that $\mathrm{FA}_{0.75} \mathrm{Cs}_{0.25}$-perovskite with higher $\mathrm{Br}$ fraction can accommodate higher content of $\mathrm{Cl}$ uniformly distributed in crystal lattice. Incorporating of $\mathrm{Cl}$ could tune the bandgap of triple-halide perovskite to $1.67 \mathrm{eV}$ with $\mathrm{Br}$ fraction limited to $15 \%$. Optimized triple-halide perovskite is more photostable upon illumination which have proved via PL measurement, as shown in Fig. 5c. Through further optimization, a large-area semitransparent device (active area $=1 \mathrm{~cm}^{2}$ ) exhibited stabilized $16.83 \%$ efficiency in an 11-point stabilized power output (SPO) test measured in National Renewable Energy Laboratory PV Device Performance laboratory. Apart from $\mathrm{Cs}$ and $\mathrm{Cl}$, DMA (dimethylammonium) was capable of reducing the reliance of increasing bandgap on increasing $\mathrm{Br}$ fraction ${ }^{48}$.

\subsection{Crystallinity optimization}

In addition, improving crystallinity of mixed-halide perovskite film is also beneficial for improving their phase stability. $\mathrm{Hu}$ et al. ${ }^{49}$ found that $\mathrm{MAPb}\left(\mathrm{Br}_{0.27} \mathrm{I}_{0.73}\right)_{3}$ perovskite films deposited on non-wetting PTAA hole transport layer owned better phase stability, as compared to those of perovskite films deposited on PEDOT:PSS layer. They attributed the better photostability of perovskite films to better crystallinity and larger grains due to the hydrophobic nature of PTAA surface. According to other works, the reduced density of grain

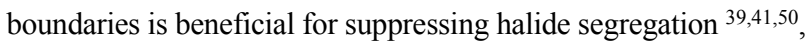
which could explain why increasing crystallinity is effective. Hillhouse et al. ${ }^{51}$ found that improving crystallinity and grain size of $\left(\mathrm{FA}_{0.83} \mathrm{Cs} 0.17\right) \mathrm{Pb}\left(\mathrm{I}_{0.66} \mathrm{Br}_{0.34}\right)_{3}$ by tailoring annealing process can improve its resistance to light-induced phase separation. Perovskite annealed at $160{ }^{\circ} \mathrm{C}$ for $50 \mathrm{~min}$ is more stable against light illumination compared to perovskite annealed at $75{ }^{\circ} \mathrm{C}$ for $10 \mathrm{~min}$. After illuminated for $5 \mathrm{~min}$ under illumination with Newport AAA Solar Simulator, perovskite annealed at higher temperature showed no peak shift in PL spectra.

\subsection{Employing other perovskite with wide bandgap}

Although I/Br hybrid perovskite absorber is the most popular component to fabricate wide bandgap sub-cell and construct tandem solar cells. It's not the only appropriate component. The easiest strategy to solve the phase segregation issue is replacing $\mathrm{I} / \mathrm{Br}$ hybrid perovskite absorber with other type of perovskite materials which also have wide bandgap.

The first option worth considering for top sub-cell in tandem configuration is all-inorganic halide perovskite. Cesium-based perovskites: $\mathrm{CsPbI}_{3}, \mathrm{CsPb}_{x} \mathrm{Br}_{1-x}$, etc., have been emerging as absorbing layer in all-inorganic perovskite photovoltaics. It has been reported that cesium-based perovskites exhibit better resistance against high temperature and light soaking ${ }^{52-55}$. Especially, the phase segregation is absent in the $\mathrm{CsPbI}_{3}$ perovskite. In addition, $\alpha-\mathrm{CsPbI}_{3}$ has a proper bandgap of 1.73 $\mathrm{eV}$ with gradually improved efficiency ${ }^{56,57}$. This provides a promising pathway for tandem device combined with silicon or 

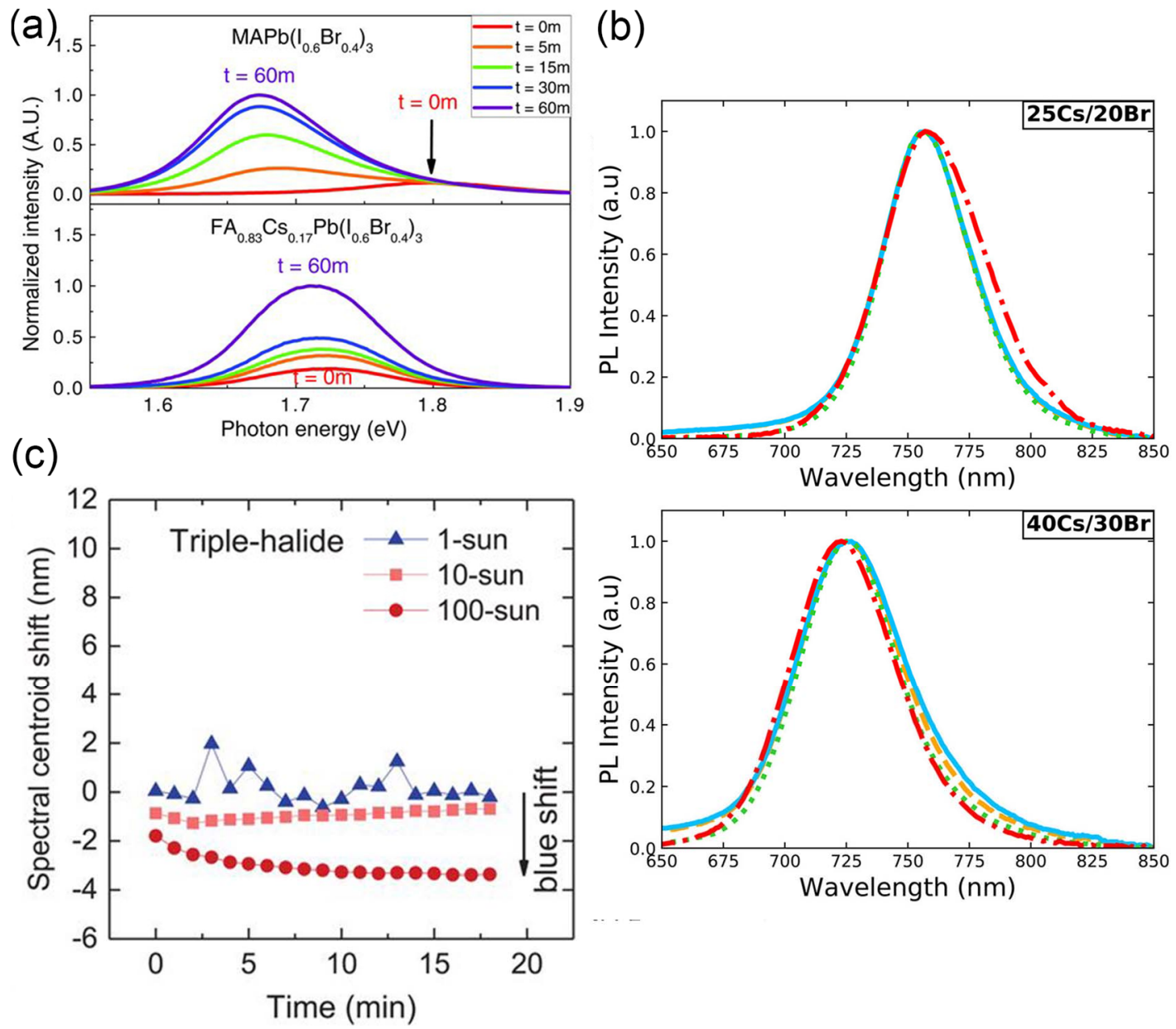

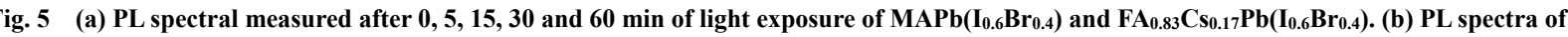
$1.68 \mathrm{eV}$ bandgap perovskite $(25 \mathrm{Cs} / 20 \mathrm{Br})$ and $1.75 \mathrm{eV}$ bandgap perovskite $(40 \mathrm{Cs} / 30 \mathrm{Br})$ after excitation. The yellow line: initial PL;

the blue line: 0.1 sun for $10 \mathrm{~min}$; the green line: 1 sun for $10 \mathrm{~min}$; the red line: 10 sun for $10 \mathrm{~min}$. (c) The shift of the PL spectral centroids of triple-halide perovskites $\left(\mathrm{I}^{-}, \mathrm{Br}^{-}\right.$and $\left.\mathrm{Cl}^{-}\right)$over time under 1-sun, 10-sun and 100-sun.

(a) Reproduced with permission from reference ${ }^{43}$, Copyright 2016, American Association for the Advancement of Science. (b) Reproduced with permission from reference ${ }^{45}$,

Copyright 2018, American Chemical Society. (c) Reproduced with permission from reference ${ }^{21}$, Copyright 2020, American Association for the Advancement of Science.

other small bandgap semiconductors. However, the photoactive phase $\alpha$ - $\mathrm{CsPbI}_{3}$ can spontaneously convert into non-photoactive $\delta$-phase (also called yellow phase) in ambient air, especially with moisture ${ }^{58}$. The $\delta$-phase is thermodynamically stable at room temperature, while black phases $(\alpha, \beta$ and $\gamma)$ are metastable ${ }^{59,60}$. Although the moisture induced phase transition issue bring about the difficulties for the employment of all-inorganic halide perovskite in tandem solar cells. Numerous works with regard to all-inorganic perovskite single junction devices have focused on addressing this concern and achieved the remarkable results ${ }^{61-69}$, which could guide the fast development of tandem solar cells based on the all-inorganic halide perovskite with wide bandgap.

The second potential option to take the place of $\mathrm{I} / \mathrm{Br}$ hybrid perovskite absorber is double perovskite. Apart from alloying I with $\mathrm{Br}$ at $\mathrm{X}$ site and replacing organic cations with $\mathrm{Cs}^{+}$, replacing $\mathrm{Pb}$ at $\mathrm{B}$ site with $\mathrm{Sb}$ or $\mathrm{Bi}$ to construct $\mathrm{Sb}$ - or Bi-based perovskites can also enlarge the bandgap. The chemical formula of perovskite with incorporating $\mathrm{Sb}$ or $\mathrm{Bi}$ at $\mathrm{B}$ site is $\mathrm{A}_{3} \mathrm{~B}_{2} \mathrm{X}_{9}$, named double perovskite, which contains a monovalent and a trivalent metal ion at $\mathrm{B}$ site to maintain the charge neutrality. Slavney et al. ${ }^{70}$ demonstrated $\mathrm{Cs}_{2} \mathrm{AgBiBr}_{6}$ as light absorber with direct bandgap of $1.95 \mathrm{eV}$ and superior thermal and light stability. However, due to the existence of deep-level defects and corresponding carrier recombination, solar cells based on these types of perovskite exhibited poor photovoltaic performance ${ }^{71,72}$, which severely limit further development of high-efficiency and stable double perovskite-based tandem solar cells.

Thirdly, the low dimensional perovskite absorber also presented the wide bandgap characteristic by introducing the bulky organic cations, like butylammonium (BA), phenethylammonium (PEA) or allylammonium (ALA). Their formula of $\mathrm{R}_{2} \mathrm{~A}_{n-1} \mathrm{~B}_{n} \mathrm{X}_{3 n-1}$ is mainly determined by the stoichiometry of organic cations in perovskites, wherein the $\mathrm{n}$ represents the layer number of the $\left[\mathrm{PbI}_{6}\right]^{2-}$ octahedral lattice. The quantum well and dielectric confinement effects, which was originated from the bulky organic cations, significantly influence their optoelectronic properties. Especially, the bandgap could be adjusted from 1.65 to $\sim 2 \mathrm{eV}$ continuously by altering the 
stoichiometry and $n$ value in the low dimensional perovskite. Meanwhile, different from I/Br hybrid perovskite absorbers, low dimensional perovskites do not suffer from the phase segregation under illumination. Also they always exhibited improved moisture resistance due to the hydrophobicity of bulky organic cations. Thus, it's promising to employ low dimensional wide bandgap perovskite into tandem solar cells and accelerate the realization of high-efficiency and stable photovoltaic tandem devices.

\section{Atmospheric instability of narrow bandgap perovskite}

The unique advantage of hybrid halide perovskite materials is not only to obtain wide bandgap perovskite by alloying iodine and bromide at $\mathrm{X}$ site, but also to realize narrow bandgap perovskite by alloying lead $(\mathrm{Pb})$ and $\operatorname{tin}(\mathrm{Sn})$ at $\mathrm{B}$ site. The proper narrow bandgap of $\mathrm{Sn}-\mathrm{Pb}$ mixed perovskite and rapidly growing efficiency of corresponding solar cell enable the success of allperovskite tandem photovoltaic device ${ }^{6,26,73}$ with both high efficiency and low levelized cost of electricity ${ }^{74}$. However, atmospheric stability of $\mathrm{Sn}-\mathrm{Pb}$ perovskite is always concerned and hampers their further development. In this section, we discussed the in-depth mechanism of atmospheric instability in narrow bandgap perovskite and systematically reviewed the optimization strategies, including introducing reducing additives, improving film morphology and forming $2 \mathrm{D} / 3 \mathrm{D}$ structure.

\subsection{Atmospheric instability and underlying mechanism}

The major obstacle of narrow bandgap $\mathrm{Sn}-\mathrm{Pb}$ perovskites is their atmospheric instability. Kanatzidis et al. ${ }^{75}$ firstly demonstrated the synthesis of a series of $\mathrm{Sn}-\mathrm{Pb}$ mixed perovskites and conducted study on their structural, electrical and optical properties. The UV-Vis spectra showed that $\mathrm{MASn}_{1-x} \mathrm{~Pb}_{x} \mathrm{I}_{3}$ possessed anomalous narrowing bandgap, even as low as $1.1 \mathrm{eV}$. $\mathrm{Sn} / \mathrm{Pb}$ alloying enables perovskite exhibit bandgap bowing effect instead of Vegard' law. Take $\mathrm{MASn}_{1-x} \mathrm{~Pb}_{x} \mathrm{I}_{3}$ as example, it possesses narrower bandgap with specific composition compared to neat $\mathrm{Sn}(1.3 \mathrm{eV})$ or neat $\mathrm{Pb}(1.55 \mathrm{eV})$ perovskite ${ }^{76,77}$. A similar trend was found by Liao et al. ${ }^{77}$ in $\left(\mathrm{FASnI}_{3}\right)_{1-x}\left(\mathrm{MAPbI}_{3}\right)_{x}$ perovskite composition. When $x=0.4,\left(\mathrm{FASnI}_{3}\right)_{0.6}\left(\mathrm{MAPbI}_{3}\right)_{0.4}$ exhibit bandgap value of $1.25 \mathrm{eV}$, which is derived from the PL emission peak of $1000 \mathrm{~nm}$. They also fabricated solar cell using this type as absorber with champion efficiency of $15.08 \%$. However, when exposed to air, the performance of $\mathrm{Sn}-\mathrm{Pb}$ mixed perovskite solar cells rapidly decline. The main reason is that $\mathrm{Sn}^{2+}$ is inevitably oxidized to $\mathrm{Sn}^{4+}$ when composed to oxygen, both in raw materials and in $\mathrm{Sn}-\mathrm{Pb}$ perovskite. Oxidation of $\mathrm{Sn}^{2+}$ would result in the formation of $V_{\mathrm{Sn}}$ and corresponding high background hole density, which may shorten carrier lifetime and carrier diffusion length ${ }^{75,78}$. In addition, $V_{\mathrm{Sn}}$ is regarded as the most popular intrinsic defect in $\mathrm{CsSnI}_{3}$ due to its low formation energy, even in the absence of oxygen, as calculated by
Kanatzidis et al. ${ }^{79}$. Thus, the major obstacle towards stability of $\mathrm{Sn}-\mathrm{Pb}$ mixed perovskite is suppressing the formation of $V_{\mathrm{Sn}}$ during device fabrication and operation.

\subsection{Introducing reducing additives}

Reducing additives are universally employed in $\mathrm{Sn}-\mathrm{Pb}$ perovskite to improve atmospheric stability through reducing intrinsic $V_{\mathrm{Sn}}$ trap density and suppressing the oxidation of $\mathrm{Sn}^{2+}$ in initial film fabrication and the following working operation. The improvement of atmospheric stability is often accompanied by the improvement of the PCE. Many researchers focused on how to reduce the concentration of $V_{\mathrm{Sn}}$ in $\mathrm{Sn}-\mathrm{Pb}$ perovskite absorber. Kumar et al. ${ }^{80}$ demonstrated $\mathrm{SnF}_{2}$ as additive to reduce the background carrier density in $\mathrm{CsSnI}_{3}$. According to their thermodynamic analysis, $\mathrm{SnF}_{2}$ increased the chemical potential of $\mathrm{Sn}\left(\mu_{\mathrm{Sn}}\right)$ and the corresponding formation energy of $V_{\mathrm{Sn}}$, thus decreasing trap density. The reduced density of $V_{\mathrm{Sn}}$ was beneficial for improving both atmospheric stability and operational stability ${ }^{29}$. In recent years, $\mathrm{SnF}_{2}$ is commonly used in achieving highly efficient and stable low bandgap $\mathrm{Sn}-\mathrm{Pb}$ perovskite solar cells ${ }^{81}$. Lin et al. ${ }^{29}$ used Sn powder as additive to reduce $\mathrm{Sn}^{4+}$ and corresponding $V_{\mathrm{Sn}}$ in $\mathrm{Sn}-\mathrm{Pb}$ perovskite precursor, as shown in Fig. 6a, b. By using this method, they obtained $24.8 \%$ efficient all-perovskite tandem solar cell with impressive operation stability. Ascorbic acid was also reported by $\mathrm{Xu}$ et al. ${ }^{82}$ to improve the efficiency and stability of $\mathrm{Sn}-\mathrm{Pb}$ perovskite. They found that ascorbic acid (AA) can effectively retard the oxidation of $\mathrm{Sn}^{2+}$ in perovskite precursor when exposed to air and form adduct with $\mathrm{SnI}_{2}$ via Lewis acid-base interaction, which reduced the trap density and improve the film morphology. The $\mathrm{Sn}-\mathrm{Pb}$ perovskite solar cells, which was processed with AA additive, exhibited better storage stability in $\mathrm{N}_{2}$-filled glovebox. Some additives were reported to improve atmospheric stability of neat-Sn perovskite such as $\mathrm{FASnI}_{3}{ }^{83,84}$ via coordination interaction with $\mathrm{Sn}^{2+}$, antioxidant function, etc. We speculate that these additives are also effective to achieve low bandgap $\mathrm{Sn}-\mathrm{Pb}$ perovskite with better atmospheric stability.

\subsection{Improving film morphology}

Improving film morphology is also effective for improving atmospheric stability. $\mathrm{Sn}-\mathrm{Pb}$ perovskites with better compactness and larger grain size own better resistance to oxygen and thus better atmospheric stability. Prasanna and coworkers 85 compared the stability of $\mathrm{FA}_{0.75} \mathrm{Cs}_{0.25} \mathrm{Sn}_{0.4} \mathrm{~Pb}_{0.6} \mathrm{I}_{3}$ perovskite films with small-grained and large-grained domains. The largegrained perovskite film exhibited larger grain size in average and reduced boundary density. They conducted lateral d.c. conductance measurement of perovskite heated at $85{ }^{\circ} \mathrm{C}$ in air. The conductance of both films first increased and then dropped at long ageing times. The small-grained perovskite film showed a greater decreased rate in conductivity compared to that of large-grained film. They attributed this phenomenon to different oxidation rates of $\mathrm{Sn}^{2+}$ in perovskite film. At the beginning, partial oxidation of perovskite will lead the formation of high density of compensating holes, which could cause the increase 
(a)
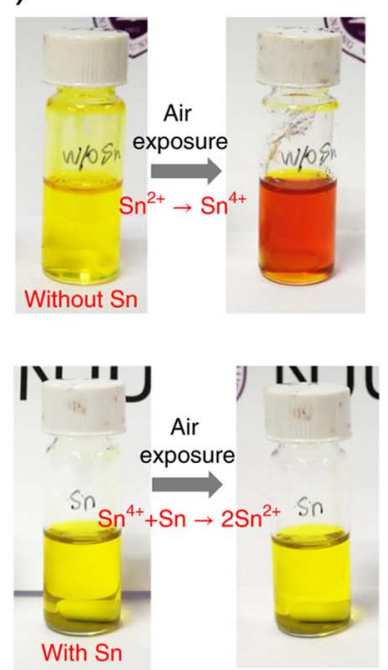

(c)

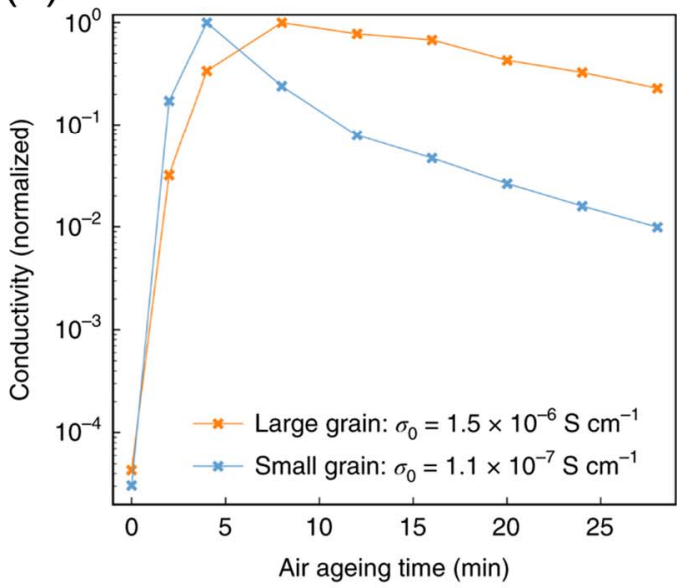

(b)
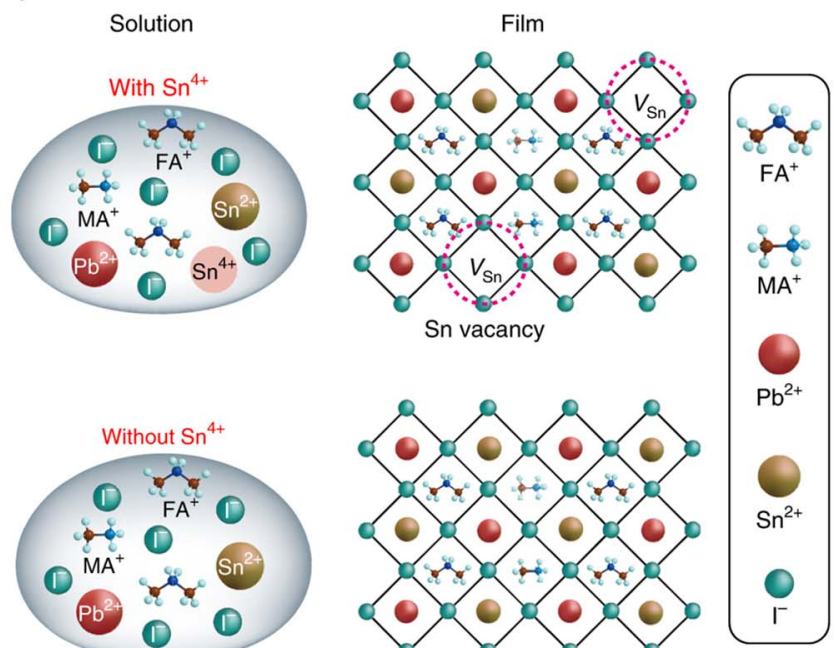

(d)

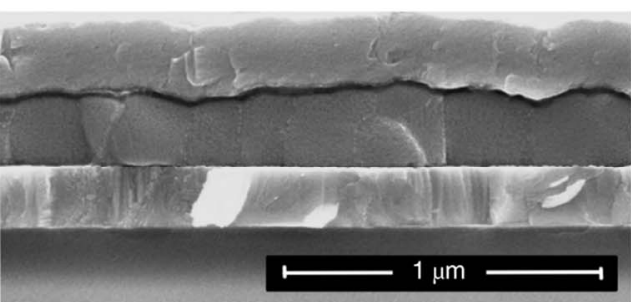

(e)
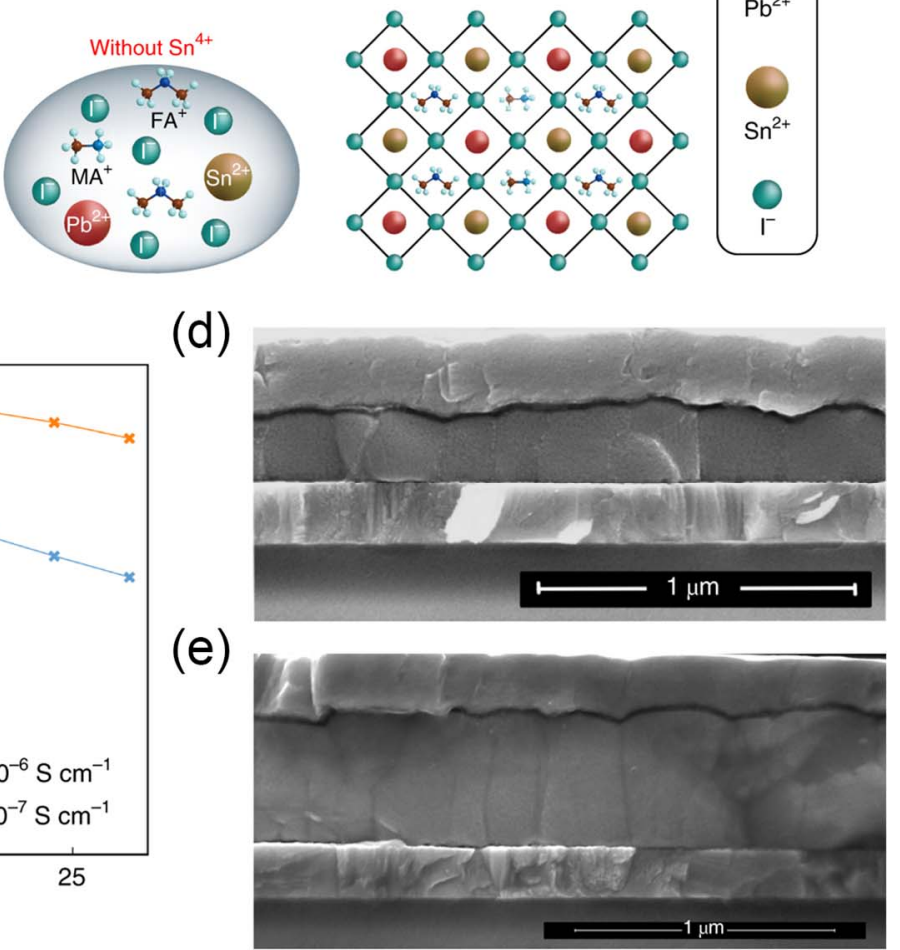

Fig. 6 (a) A photograph of Sn-Pb precursor with and without Sn powders as additives when exposed in air. The color change from brightyellow to orange indicates the oxidation of $\mathrm{Sn}^{2+}$ to $\mathrm{Sn}^{4+}$. (b) A schematic illustration of the mechanism of reduced $\mathrm{Sn}$ vacancies introducing $\mathrm{Sn}$ powders. (c) The normalized d.c. conductance of $\mathrm{FA}_{0.75} \mathrm{Cs}_{0.25} \mathrm{Sn}_{0.4} \mathrm{~Pb}_{0.6} \mathrm{I}_{3}$ films of different film compactness and size over time heated at $85{ }^{\circ} \mathrm{C}$ in air.

The initial values of the conductance are denoted as $\sigma_{0}$ in the legend. Cross-sectional SEM images of small-grained (d) and large-grained (e) perovskite devices (on bare ITO without hole transport layer) after ageing in air at $85{ }^{\circ} \mathrm{C}$ for $500 \mathrm{~h}$.

(a, b) Adapted from reference ${ }^{29}$, Copyright 2019, Macmillan Publishers Limited. (c, d, e) Adapted from reference ${ }^{85}$, Copyright 2019, Macmillan Publishers Limited.

in conductivity ${ }^{75,79}$. As time goes on, more and more tin dioxide $\left(\mathrm{SnO}_{2}\right)$ appeared at grain boundary according to their observation from x-ray photoelectron spectra (XPS) spectrum. The larger amounts of insulating $\mathrm{SnO}_{2}$, attributed to the faster oxidation at wider and more frequent boundaries in smallgrained film, resulted in a faster drop in conductance (Fig. 6ce). This suggested that better atmospheric stability could be achieved in $\mathrm{Sn}-\mathrm{Pb}$ perovskite with improved film morphology.

\subsection{Forming 2D/3D structure}

In addition, the combination of two-dimensional (2D) and three-dimensional (3D) perovskite to form $2 \mathrm{D} / 3 \mathrm{D}$ structure is beneficial for improving atmospheric stability of $\mathrm{Sn}-\mathrm{Pb}$ perovskite solar cells. Layered perovskite at grain boundaries could effectively hinder the diffusion of oxygen into crystal lattice, suggesting the better atmospheric and operation stability ${ }^{86}$.
Tong et al. ${ }^{27}$ used guanidinium thiocyanate (GuaSCN) as additive to improve the efficiency and stability of $\mathrm{Sn}-\mathrm{Pb}$ perovskite solar cells. They found that $2 \mathrm{D}$ perovskite structure was formed at grain boundaries with the addition of GuaSCN, which could hinder the oxygen diffusion into crystal lattice to suppress the oxidation of $\mathrm{Sn}^{2+}$ and block the diffusion of $\mathrm{Sn}$ out of grains. The carrier lifetime of perovskite film was increased from $\sim 139$ to $\sim 1232$ ns after adding $7 \%$ GuaSCN, as shown in Fig. $7 \mathrm{a}$, which indicated the suppressed carrier recombination. The GuaSCN-modified $\mathrm{Sn}-\mathrm{Pb}$ perovskite solar cells and corresponding 4T tandem solar cell exhibited impressive operation stability at MPP tracking. Recently, Wei et al. ${ }^{30}$ introduced the low concentration of phenethylammonium iodide (PEAI) in antisolvent to fabricate $1.25 \mathrm{eV} \mathrm{Sn-Pb}$ perovskite solar cells with good operation stability. The addition of PEAI formed 
(a)
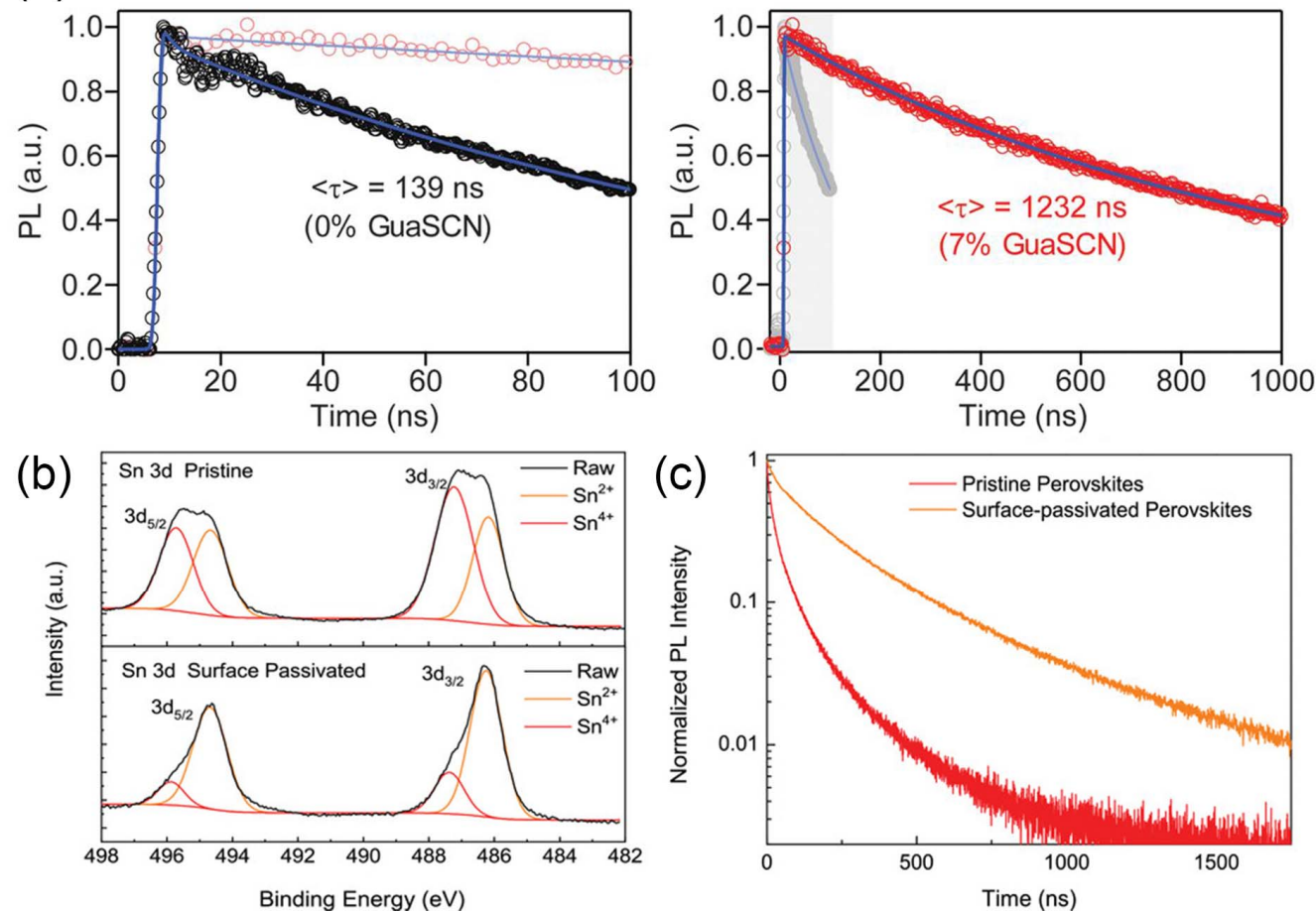

Fig. 7 (a) Carrier lifetime measured by TRPL of perovskite films without and with GuaSCN. (b) The XPS spectra of Sn $3 d$ of pristine and surface passivated perovskite film. (c) The TRPL decay of perovskite films probed from top side of samples.

(a) Reproduced with permission from reference ${ }^{27}$, Copyright 2019, American Association for the Advancement of Science.

(b, c) Reproduced with permission from reference ${ }^{30}$, Copyright 2020, Wiley-VCH.

ultrathin layered perovskite at film surface, which inhibited the oxidation of Sn, as proved by the XPS of Sn $3 d$ shown in Fig. 7b. The $\mathrm{Sn}^{4+}$ signal was obviously reduced. The TRPL characterization, as shown in Fig. 7c, indicated that PEAImodified perovskite exhibited enhanced carrier lifetime. The $\mathrm{PCE}$ of $\mathrm{Sn}-\mathrm{Pb}$ perovskite solar cells with the addition of PEAI dropped to $90 \%$ after $8.6 \mathrm{~h}$ at MPP tracking, which exhibited 200 -fold enhancement compared to reference device. The $2 \mathrm{~T}$ tandem device remained $95 \%$ of initial efficiency after $65 \mathrm{~h}$ at MPP tracking.

\section{Intrinsic instability of perovskite}

Due to the strict requirements of tandem solar cells, the most popular composition of perovskite sub-cells in tandem solar cells is $\mathrm{I}-\mathrm{Br}$ alloying perovskite for wide bandgap, and $\mathrm{Sn}-\mathrm{Pb}$ alloying perovskite for narrow bandgap. Researchers are thus focusing on the most concerning stability issue of these sub-cells, namely the phase instability and atmospheric instability. In addition to these apparent issues, owing to relatively soft ionic crystal structure, the hybrid halide perovskite exhibited intrinsic instability, which is also one of the main obstacles lying at the approach towards the commercialization of perovskite-based tandem solar cells ${ }^{87}$. In this section, we discussed the intrinsic instability of perovskite materials, with the focus on the moisture and thermal instability and ion migration. These two issues have not been investigated carefully in perovskite-based tandem solar cells yet, but they need to be addressed well.

\subsection{Moisture and thermal instability related with MA components of perovskite}

The widely employed cation, namely methylammonium $\left(\mathrm{CH}_{3} \mathrm{NH}_{3}, \mathrm{MA}\right)$, at A site in $\mathrm{I}-\mathrm{Br}$ alloying perovskite or $\mathrm{Sn}-\mathrm{Pb}$ alloying perovskite absorbers, is reported to bring about various and serious instability problems. First, its hygroscopicity makes lead perovskite to absorb water and form hydrate $\left(\mathrm{CH}_{3} \mathrm{NH}_{3}\right)_{4} \mathrm{PbI}_{6} \cdot 2 \mathrm{H}_{2} \mathrm{O}{ }^{88}$ when exposed to humid environment and may further degradation ${ }^{89}$. In addition, $\mathrm{CH}_{3} \mathrm{NH}_{3} \mathrm{I}$ will decompose into $\mathrm{CH}_{3} \mathrm{I}$ and $\mathrm{NH}_{3}$ via so-called reverse Menshutkin reaction under thermal treatment ${ }^{90}$. Low formation energy of $\mathrm{MAPbI}_{3}$, as calculated by DFT, was also reported to be responsible for the instability when subjected to heat and light illumination ${ }^{91,92}$. According to IEC standards, perovskite materials must undergo thermal stability test at $85{ }^{\circ} \mathrm{C}$ when integrating with silicon to make tandem devices. Therefore, many works have been reported to improve stability of MAbased perovskite. Researchers found that replacing MA with formamidinium $\left(\mathrm{CH}\left(\mathrm{NH}_{2}\right)_{2}, \mathrm{FA}\right)$ cation or inorganic cations such as cesium $(\mathrm{Cs})$ and rubidium $(\mathrm{Rb})$ can effectively improve the intrinsic thermal stability of perovskite ${ }^{93,94}$, as shown in Fig. 8a. Therefore, double-cation or triple-cation perovskite systems such as FAMA, FACs and FAMACs were developed to achieve better chemical stability. Lee et al. ${ }^{95}$ reported $\mathrm{FA}_{0.9} \mathrm{Cs}_{0.1} \mathrm{PbI}_{3}$ perovskite as an alternative to $\mathrm{FAPbI}_{3}$ and $\mathrm{MAPbI}_{3}$ with $19.0 \%$ 
(a)

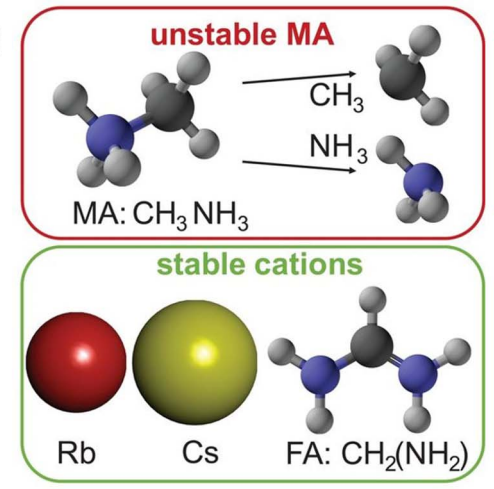

(b)

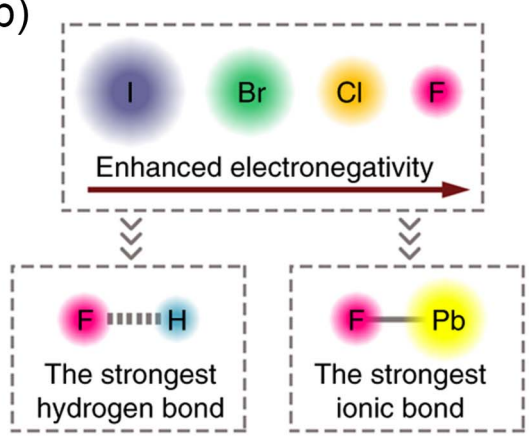

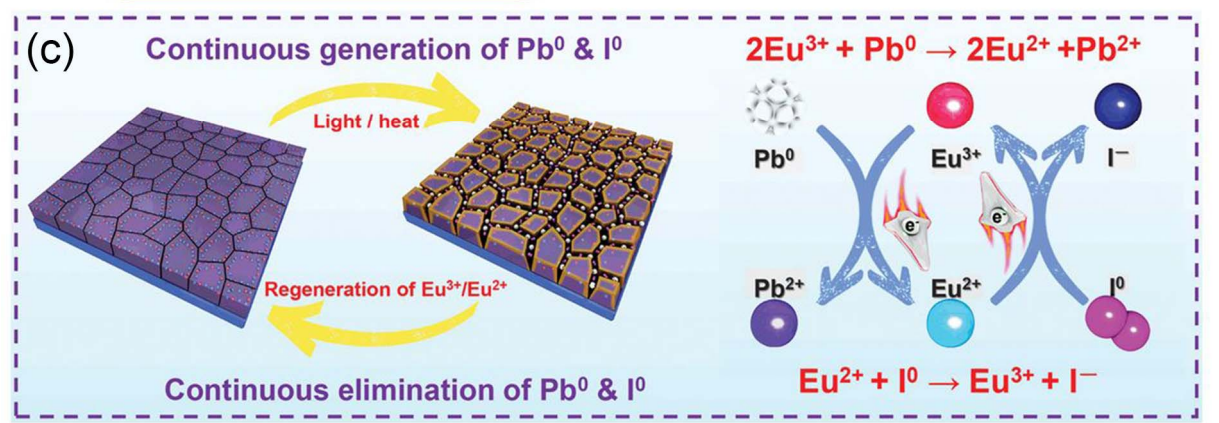

Fig. 8 (a) A schematic illustration of the structure of MA and thermally more stable Rb, Cs and FA. (b) A schematic illustration of hydrogen bond between halogen and MA/FA, and ionic bond between halogen and lead. (c) A proposed mechanism diagram of continuous elimination of $\mathrm{Pb}^{0}$ and $\mathrm{I}^{0}$ and regeneration of $\mathrm{Eu}^{3+}-\mathrm{Eu}^{2+}$ ion pair.

(a) Reproduced with permission from reference ${ }^{90}$, Copyright 2018, American Association for the Advancement of Science. (b) Adapted from reference ${ }^{103}$, Copyright 2019 ,

Macmillan Publishers Limited. (c) Reproduced with permission from reference ${ }^{104}$, Copyright 2019, American Association for the Advancement of Science.

efficiency. They also found that $\mathrm{FA}_{0.9} \mathrm{Cs}_{0.1} \mathrm{PbI}_{3}$ was more robust against light illumination and humidity. Saliba et al. 93 discovered $\mathrm{Rb}_{x} \mathrm{Cs}_{y} \mathrm{FA}_{(100-x-y)} \mathrm{PbI}_{3}$ perovskite without MA showed improved long-term stability. They also used polymer to passivate interface between the charge transport layer and perovskite, reaching stabilized efficiency of $20.35 \%$ and a small loss after ageing at maximum power point (MPP) for $1000 \mathrm{~h}$. From the discussion above, we consider that to construct the stable perovskite-based tandem solar cells, the component of MA needs to reduce as much as possible to improve the intrinsic thermal stability.

\subsection{Ion migration related with defects of perovskite}

It's widely accepted that defect states in perovskite can seriously affect long-term stability of corresponding devices, even in tandem solar cells ${ }^{96-101}$. Unlike other covalently bonded stable semiconductor materials such as silicon and germanium, constituting ions of perovskite can migrate within the film or even cross the interface. This phenomenon is aggravated when defect density is high ${ }^{102,103}$, because defects always act as channels to facilitate ion migration ${ }^{104}$. The ion-migration behavior has been considered as the main course of $J-V$ hysteresis and have profound effects on long-term stability of perovskite-based photovoltaic devices ${ }^{105,106}$. Thus, eliminating defects and suppressing ion migration play an important role in improving the working stability of perovskite-based tandem solar cells. Li et al. ${ }^{107}$ proposed a novel method to passivate organic cation and lead vacancies via chemical bond modulation using Sodium fluoride (NaF). As shown in Fig. 8b, the fluoride ion interacted with both organic cations via both hydrogen bonds, and lead via strong ionic bond, which effectively suppresses ion migration. The corresponding device exhibited excellent long-term stability, remaining $90 \%$ of original efficiency after $1000 \mathrm{~h}$ of operation test under MPP tracking. In addition, some defects will form spontaneously in perovskite layer during ageing process of device and do harm to long-term stability. For example, $\mathrm{Pb}^{2+}$ and $\mathrm{I}^{-}$ions are chemically reactive to be easily converted into $\mathrm{Pb}^{0}$ and $\mathrm{I}^{0}$ defects respectively ${ }^{108}$. This process will severely decompose the perovskite layer and decline the performance of device during operation. Eliminating these defects is beneficial for improving long-term stability. Wang et al. ${ }^{108}$ introduced the " $\mathrm{Eu}^{3+}-\mathrm{Eu}^{2+}$ " ion pair as redox shuttle into $\mathrm{Pb}$-I perovskite to simultaneously eliminate both $\mathrm{Pb}^{0}$ and $\mathrm{I}^{0}$ defects. As shown in Fig. 8c, they found that $\mathrm{Eu}^{3+}$ could oxidize $\mathrm{Pb}^{0}$ to $\mathrm{Pb}^{2+}$, while the reduction product of $\mathrm{Eu}^{2+}$ could reduce $\mathrm{I}^{0}$ to $\mathrm{I}^{-}$and be regenerated into $\mathrm{Eu}^{3+}$ itself. This method can eliminate $\mathrm{Pb}^{0}$ and $\mathrm{I}^{0}$ simultaneously in a cyclical transition. The full devices with $\mathrm{Eu}^{3+}$ incorporated exhibited impressive performance and stability, maintaining $91 \%$ of initial PCE after $500 \mathrm{~h}$ MPP tracking. Other methods such as incorporating low dimensional perovskite structures to form 2D/3D hybrid structure ${ }^{109-111}$, enlarging the grain size in polycrystalline perovskite film and improving crystallinity via additives (e.g., chlorine ${ }^{46-47,112-113}$ ) or solvent annealing ${ }^{114-118}$ method are also effective for suppressing ion migration. 


\section{Instability related to interconnecting layer}

In a typical $2 \mathrm{~T}$ configuration, two sub-cells are electrically and mechanically connected by the interconnecting layer, which can be classified into two types: recombination layer and tunnel junction. The recombination layer, usually transparent electrode such as ITO, possesses excellent electrical conductivity and transmittance. Tunnel junction is composed of heavily n-doped and p-doped layer, facilitating electrons and holes recombination. In addition to the instability of perovskite subcells, the instability of interconnecting layers are also crucial to perovskite-based tandem solar cell. In this section, we briefly summarized the instability caused by interconnecting layer, including the instability caused by fabrication process and interfacial reaction between interconnecting layer and perovskite.

\subsection{Instability caused by fabrication process of interconnecting layer}

The recombination layer is widely used in perovskite/perovskite tandem configuration, which usually contains an inorganic transparent electrode such as sputtered ITO or an organic polymer layer such as PEDOT:PSS. In the process of sputtering ITO, high temperature and the sputter particles with high energy could cause a severe damage to the perovskite sub-cell underneath. To solve this problem, McGehee et al. ${ }^{119}$ introduced aluminum doped $\mathrm{ZnO}$ (AZO) nanoparticles as "buffer layer" to protect the underlying electron transport layer and perovskite active layer from damage during the subsequent sputter process of ITO. The buffer layer had proper bandgap and work function, enabling itself as an electronselective contact simultaneously. The initial efficiency of semitransparent perovskite device without AZO buffer layer $(6 \%$ efficiency) was worse than device with buffer layer $(12.3 \%$ efficiency). This is most likely due to the damage during sputter process of ITO. The semitransparent device had a $\mathrm{T}_{80}$ lifetime of $124 \mathrm{~h}$ when operated at $100{ }^{\circ} \mathrm{C}$ under LED illumination. Introducing $\mathrm{MoO}_{X}$ as a buffer layer is also reported previously ${ }^{120}$. The evaporated $\mathrm{MoO}_{x}$ layer, used to be the passivated holeselective contact in silicon heterojunction solar cell, has been proven to be able to protect perovskite active layer underneath from sputter damage.

In addition to the protection from sputter process, a careful protection from solvent damage to perovskite during spincoating process is also vital. It is difficult to use orthogonal solvents method to fabricate two perovskite sub-cells in a solution-processed perovskite/perovskite tandem. This is because the perovskite precursor is able to dissolve the previously spin-coated perovskite active layer underneath. Thus, the interconnecting layer must be designed to have robust resistance against subsequent solution-based deposition process. Chang et al. ${ }^{121}$ designed an interconnecting layer composed of cross-linked PTAA and hexamethonium bromide (HMB) doped $\mathrm{PC}_{61} \mathrm{BM}$ in perovskite/perovskite tandem. They used 1,2-bis[4- (azidomethyl) phenyl]-1,2-diphenylethene (TPE-MN3) to crosslink PTAA and increase the thickness of PTAA, in order to improve the solvent resistance. Besides, the tris-[1(trifluoroethanoyl)-2-(trifluoro-methyl) ethane1,2-dithiolene] $\left(\mathrm{Mo}\left(\mathrm{tfdCOCF}_{3}\right)_{3}\right)$ was used to dope PTAA to improve electrical conductivity of a thicker PTAA film. After encapsulation with alumina $\left(\mathrm{Al}_{2} \mathrm{O}_{3}\right)$, a $2 \mathrm{~T}$ tandem device remained more than $70 \%$ of its initial efficiency after $2100 \mathrm{~h}$ under MPP tracking in ambient air $\left(30^{\circ} \mathrm{C}, 60 \%\right.$ relative humidity). PEDOT:PSS is widely used as hole transport layer and can also be served as transparent electrode in recombination layer due to its high conductivity and transparency. However, it is usually dispersed in water, which would cause damage to the perovskite layer if it is directly spin-coated on perovskite sub-cell. Zhou et al. ${ }^{122}$ demonstrated a dry-transferred method to deposit PEDOT:PSS in interconnecting layer as transparent electrode. This is an effective method to avoid directly spin-coating aqueous solution. In summary, the interconnecting layer needs to be modified to protect perovskite active layers underneath from damage of fabrication process of functional layers sequentially deposited.

\subsection{Interfacial reaction between interconnecting layer and perovskite}

Most recombination layer used in perovskite/perovskite tandems contains an n-type and a p-type layer, that is, carrier transport layers in perovskite sub-cells. They are used to extract electrons and holes from different sub-cells, by directly contacting with perovskite active layer and electrodes. The interfacial reaction between carrier transport layers in recombination layer and perovskite can also result in instability of perovskite-based tandems. As discussed above, Huang et al. ${ }^{31}$ demonstrated a simplified interconnecting layer composed of $\mathrm{C}_{60}$ and $\mathrm{SnO}_{1.76}$, improving the photostability of perovskite/ perovskite tandem device. The $\mathrm{SnO}_{1.76}$ film was fabricated via low-temperature atomic layer deposition (ALD) process, serving as hole transport layer in narrow bandgap $\mathrm{Sn}-\mathrm{Pb}$ perovskite subcell. It is found that the photocurrent output of single junction $\mathrm{Sn}-\mathrm{Pb}$ perovskite solar cell with $\mathrm{SnO}_{1.76}$ as hole transport layer was more stable than device utilized commonly used PEDOT:PSS under MPP condition. The improved stability could be attributed to the replacement of PEDOT:PSS, as PEDOT:PSS could cause damage to stability of single junction perovskite solar cell through the corrosion of ITO and the interfacial reaction with $\mathrm{Sn}-\mathrm{Pb}$ perovskite ${ }^{85,123}$. In addition, the strategies reported in the single junction perovskite solar cell to suppress the interfacial chemical reaction between perovskite and metal electrode (such as $\mathrm{I}^{-}$and $\mathrm{Ag}$ ), may also be helpful for improving the stability of perovskite-based tandem solar cell.

\section{Summary and outlook}

Perovskite-based tandem solar cells have demonstrated impressive power conversion efficiency that can satisfy the requirement for commercial applications. However, long-term stability of perovskite-based tandem devices is still the most 
serious problem for its economic feasibility. In this review, we have first summarized the recent advances in the stability of perovskite-based tandem solar cells, including perovskite/silicon and perovskite/perovskite tandem devices. Then, we specially discussed the phase instability of wide bandgap perovskite, atmospheric instability of narrow bandgap perovskite and the potential intrinsic instability issue in tandem solar cells, as well as the corresponding strategies to tackle these instability issues. At last, we briefly discussed instability issues related with the interconnecting layer. We highlight that intrinsic instability of perovskite sub-cells is the major cause for the instability of perovskite-based tandem solar cells.

At present, perovskite/silicon tandems are considered as the most attractive perovskite-based configuration. The semitransparent perovskite sub-cell with wide bandgap perovskites as absorbers can be utilized as a supplement for single junction solar cell, reducing energy loss and further improving efficiency. Considering that the perovskite material is very sensitive to the external environment, encapsulation may be an evitable method to improve device stability, which needs to be further explored. Perovskite-based tandem devices have demonstrated excellent PCEs, leaving the potential long-term instability as the major obstacle. At present, there is few publications devoted to understanding improving the long-term stability of perovskite-based tandem devices. Researchers are currently focusing on improving the instability of individual parts of perovskite-based tandem devices, i.e., the phase instability of top sub-cell based on mixed halide perovskite or atmospheric instability of $\mathrm{Sn}-\mathrm{Pb}$ sub-cell in all-perovskite tandem devices. It needs to be further explored that whether two sub-cells would affect each other especially in $2 \mathrm{~T}$ configuration during working conditions, resulting in additional instability problem. Future work should pay more attention on the overall instability issues of perovskite-based tandem devices during working conditions.

In addition, standard testing procedures and protocols for perovskite-based tandem stability needs to be established. Recently, a consensus on procedures for testing perovskite solar cell stability has been published ${ }^{124}$. This guideline is beneficial for setting a standard to compare stability data from different works. A consensus that pays more attention to the perovskitebased tandem devices is also needed in the future. We expect that with the more and deeper understanding of the origin of perovskite-based tandem devices' instability, lifetime up to 20 years can be achieved via modification of perovskite materials and optimization of tandem device structure.

\section{References}

(1) Branker, K.; Pathak, M. J. M.; Pearce, J. M. Renew. Sust. Energ. Rev 2011, 15, 4470. doi: 10.1016/j.rser.2011.07.104

(2) Shockley, W.; Queisser, H. J. J. Appl. Phys. 1961, 32, 510. doi: $10.1063 / 1.1736034$

(3) Vos, A. D. J. Phys. D: Appl. Phys. 1980, 13, 839. doi: $10.1088 / 0022-3727 / 13 / 5 / 018$

(4) Filipič, M.; Löper, P.; Niesen, B.; De Wolf, S.; Krč, J.; Ballif, C.; Topič, M. Opt. Express 2015, 23, A263. doi: 10.1364/OE.23.00A263

(5) Albrecht, S.; Saliba, M.; Correa-Baena, J. P.; Jäger, K.; Korte, L.; Hagfeldt, A.; Grätzel, M.; Rech, B. J. Opt. 2016, 18, 064012. doi: 10.1088/2040-8978/18/6/064012

(6) Eperon, G. E.; Leijtens, T.; Bush, K. A.; Prasanna, R.; Green, T.; Wang, J. T. W.; McMeekin, D. P.; Volonakis, G.; Milot, R. L.; May, R.; et al. Science 2016, 354, 861. doi: 10.1126/science.aaf9717

(7) Jaysankar, M.; Filipič, M.; Zielinski, B.; Schmager, R.; Song, W.; Qiu, W.; Paetzold, U. W.; Aernouts, T.; Debucquoy, M.; Gehlhaar, R.; et al. Energy Environ. Sci. 2018, 11, 1489. doi: $10.1039 / \mathrm{C} 8 \mathrm{EE} 00237 \mathrm{~A}$

(8) https://www.nrel.gov/pv/assets/pdfs/best-research-cellefficiencies.20200406.pdf (accessed Dar April 2020)

(9) Ogomi, Y.; Morita, A.; Tsukamoto, S.; Saitho, T.; Fujikawa, N.; Shen, Q.; Toyoda, T.; Yoshino, K.; Pandey, S. S.; Ma, T.; et al. J. Phys. Chem. Lett. 2014, 5, 1004. doi: 10.1021/jz5002117

(10) Zhou, Z.; Cui, Y.; Deng, H. X.; Huang, L.; Wei, Z.; Li, J. Appl. Phys. Lett. 2017, 110, 113901. doi: 10.1063/1.4978598

(11) Filip, M. R.; Eperon, G. E.; Snaith, H. J.; Giustino, F. Nat. Commun. 2014, 5, 5757. doi: $10.1038 /$ ncomms 6757

(12) Eperon, G. E.; Stranks, S. D.; Menelaou, C.; Johnston, M. B.; Herz, L. M.; Snaith, H. J. Energy Environ. Sci. 2014, 7, 982. doi: $10.1039 / \mathrm{C} 3 \mathrm{EE} 43822 \mathrm{H}$

(13) Eperon, G. E.; Paternò, G. M.; Sutton, R. J.; Zampetti, A.; Haghighirad, A. A.; Cacialli, F.; Snaith, H. J. J. Mater. Chem. A 2015, 3, 19688. doi: 10.1039/C5TA06398A

(14) Chen, B.; Yu, Z. J.; Manzoor, S.; Wang, S.; Weigand, W.; Yu, Z.; Yang, G.; Ni, Z.; Dai, X.; Holman, Z. C.; et al. Joule 2020, 4, 850 doi: $10.1016 /$ j.joule.2020.01.008

(15) Shen, H.; Duong, T.; Peng, J.; Jacobs, D.; Wu, N.; Gong, J.; Wu, Y.; Karuturi, S. K.; Fu, X.; Weber, K.; et al. Energy Environ. Sci. 2018, 11, 394. doi: 10.1039/C7EE02627G

(16) Liu, Y.; Renna, L. A.; Bag, M.; Page, Z. A.; Kim, P.; Choi, J.; Emrick, T.; Venkataraman, D.; Russell, T. P. ACS Appl. Mater. Interfaces 2016, 8 , 7070. doi: 10.1021/acsami.5b12740

(17) Gao, K.; Zhu, Z.; Xu, B.; Jo, S. B.; Kan, Y.; Peng, X.; Jen, A. K. Y. Adv. Mater. 2017, 29, 1703980. doi: 10.1002/adma.201703980

(18) Li, C.; Wang, Y.; Choy, W. C. H. Small Methods 2020, 4, 2000093. doi: $10.1002 /$ smtd.202000093

(19) Bailie, C. D.; Christoforo, M. G.; Mailoa, J. P.; Bowring, A. R.; Unger, E. L.; Nguyen, W. H.; Burschka, J.; Pellet, N.; Lee, J. Z.; Grätzel, M.; et al. Energy Environ. Sci. 2015, 8, 956. 


\section{doi: 10.1039/C4EE03322A}

(20) https://www.oxfordpv.com/news/oxford-pv-perovskite-solar-cellachieves-28-efficiency. (accessed Dar April 2020)

(21) Xu, J.; Boyd, C. C.; Yu, Z. J.; Palmstrom, A. F.; Witter, D. J.; Larson, B. W.; France, R. M.; Werner, J.; Harvey, S. P.; Wolf, E. J.; et al. Science 2020, 367, 1097. doi: 10.1126/science.aaz5074

(22) Bush, K. A.; Palmstrom, A. F.; Yu, Z. J.; Boccard, M.; Cheacharoen, R.; Mailoa, J. P.; McMeekin, D. P.; Hoye, R. L. Z.; Bailie, C. D.; Leijtens, T.; et al. Nat. Energy 2017, 2, 17009. doi: 10.1038/nenergy.2017.9

(23) Sahli, F.; Werner, J.; Kamino, B. A.; Bräuninger, M.; Monnard, R.; Paviet-Salomon, B.; Barraud, L.; Ding, L.; Diaz Leon, J. J.; Sacchetto, D.; et al. Nat. Mater. 2018, 17, 820. doi: $10.1038 / \mathrm{s} 41563-018-0115-4$

(24) Kim, D.; Jung, H. J.; Park, I. J.; Larson, B. W.; Dunfield, S. P.; Xiao, C.; Kim, J.; Tong, J.; Boonmongkolras, P.; Ji, S. G.; et al. Science 2020, 368, 155. doi: 10.1126/science.aba3433

(25) Hou, Y.; Aydin, E.; De Bastiani, M.; Xiao, C.; Isikgor, F. H.; Xue, D. J.; Chen, B.; Chen, H.; Bahrami, B.; Chowdhury, A. H.; et al. Science 2020, 367, 1135. doi: 10.1126/science.aaz3691

(26) Zhao, D.; Chen, C.; Wang, C.; Junda, M. M.; Song, Z.; Grice, C. R.; Yu, Y.; Li, C.; Subedi, B.; Podraza, N. J.; et al. Nat. Energy 2018, 3, 1093. doi: 10.1038/s41560-018-0278-x

(27) Tong, J.; Song, Z.; Kim, D. H.; Chen, X.; Chen, C.; Palmstrom, A. F.; Ndione, P. F.; Reese, M. O.; Dunfield, S. P.; Reid, O. G.; et al. Science 2019, 364, 475. doi: 10.1126/science.aav7911

(28) Yang, Z.; Yu, Z.; Wei, H.; Xiao, X.; Ni, Z.; Chen, B.; Deng, Y.; Habisreutinger, S. N.; Chen, X.; Wang, K.; et al. Nat. Commun. 2019, 10, 4498. doi: 10.1038/s41467-019-12513-x

(29) Lin, R.; Xiao, K.; Qin, Z.; Han, Q.; Zhang, C.; Wei, M.; Saidaminov, M. I.; Gao, Y.; Xu, J.; Xiao, M.; et al. Nat. Energy 2019, 4, 864. doi: $10.1038 / \mathrm{s} 41560-019-0466-3$

(30) Wei, M.; Xiao, K.; Walters, G.; Lin, R.; Zhao, Y.; Saidaminov, M. I.; Todorović, P.; Johnston, A.; Huang, Z.; Chen, H.; et al. Adv. Mater. 2020, 32, 1907058. doi: 10.1002/adma.201907058

(31) Yu, Z.; Yang, Z.; Ni, Z.; Shao, Y.; Chen, B.; Lin, Y.; Wei, H.; Yu, Z. J.; Holman, Z.; Huang, J. Nat. Energy 2020, 5, 657. doi: 10.1038/s41560-020-0657-y

(32) Han, Q.; Hsieh, Y. T.; Meng, L.; Wu, J. L.; Sun, P.; Yao, E. P.; Chang, S. Y.; Bae, S. H.; Kato, T.; Bermudez, V.; et al. Science 2018, 361, 904. doi: 10.1126/science.aat5055

(33) Al-Ashouri, A.; Magomedov, A.; Roß, M.; Jošt, M.; Talaikis, M.; Chistiakova, G.; Bertram, T.; Márquez, J. A.; Köhnen, E.; Kasparavičius, E.; et al. Energy Environ. Sci. 2019, 12, 3356. doi: 10.1039/C9EE02268F

(34) Leijtens, T.; Bush, K. A.; Prasanna, R.; McGehee, M. D. Nat. Energy
2018, 3, 828 doi: 10.1038/s41560-018-0190-4

(35) Eperon, G. E.; Hörantner, M. T.; Snaith, H. J. Nat. Rev. Chem. 2017, 1, 0095. doi: 10.1038/s41570-017-0095

(36) Noh, J. H.; Im, S. H.; Heo, J. H.; Mandal, T. N.; Seok, S. I. Nano Lett. 2013, 13, 1764. doi: 10.1021/n1400349b

(37) Kulkarni, S. A.; Baikie, T.; Boix, P. P.; Yantara, N.; Mathews, N.; Mhaisalkar, S. J. Mater. Chem. A 2014, 2, 9221. doi: 10.1039/C4TA00435C

(38) Hoke, E. T.; Slotcavage, D. J.; Dohner, E. R.; Bowring, A. R.; Karunadasa, H. I.; McGehee, M. D. Chem. Sci. 2015, 6, 613. doi: 10.1039/C4SC03141E

(39) Tang, X.; van den Berg, M.; Gu, E.; Horneber, A.; Matt, G. J.; Osvet, A.; Meixner, A. J.; Zhang, D.; Brabec, C. J. Nano Lett. 2018, 18, 2172. doi: 10.1021/acs.nanolett.8b00505

(40) Brivio, F.; Caetano, C.; Walsh, A. J. Phys. Chem. Lett. 2016, 7, 1083. doi: 10.1021/acs.jpclett.6b00226

(41) Bischak, C. G.; Hetherington, C. L.; Wu, H.; Aloni, S.; Ogletree, D. F.; Limmer, D. T.; Ginsberg, N. S. Nano Lett. 2017, 17, 1028. doi: 10.1021/acs.nanolett.6b04453

(42) Barker, A. J.; Sadhanala, A.; Deschler, F.; Gandini, M.; Senanayak, S. P.; Pearce, P. M.; Mosconi, E.; Pearson, A. J.; Wu, Y.; Srimath Kandada, A. R.; et al. ACS Energy Lett. 2017, 2, 1416. doi: 10.1021/acsenergylett.7b00282

(43) McMeekin, D. P.; Sadoughi, G.; Rehman, W.; Eperon, G. E.; Saliba, M.; Hörantner, M. T.; Haghighirad, A.; Sakai, N.; Korte, L.; Rech, B.; et al. Science 2016, 351, 151. doi: 10.1126/science.aad5845

(44) Duong, T.; Wu, Y.; Shen, H.; Peng, J.; Fu, X.; Jacobs, D.; Wang, E. C.; Kho, T. C.; Fong, K. C.; Stocks, M.; et al. Adv. Energy Mater. 2017, 7, 1700228. doi: 10.1002/aenm.201700228

(45) Bush, K. A.; Frohna, K.; Prasanna, R.; Beal, R. E.; Leijtens, T.; Swifter, S. A.; McGehee, M. D. ACS Energy Lett. 2018, 3, 428. doi: $10.1021 /$ acsenergylett. $7 \mathrm{~b} 01255$

(46) Kim, M.; Kim, G. H.; Lee, T. K.; Choi, I. W.; Choi, H. W.; Jo, Y.; Yoon, Y. J.; Kim, J. W.; Lee, J.; Huh, D.; et al. Joule 2019, 3, 2179. doi: 10.1016/j.joule.2019.06.014

(47) Chen, Q.; Zhou, H.; Fang, Y.; Stieg, A. Z.; Song, T. B.; Wang, H. H.; Xu, X.; Liu, Y.; Lu, S.; You, J.; et al. Nat. Commun. 2015, 6, 7269. doi: $10.1038 /$ ncomms 8269

(48) Palmstrom, A. F.; Eperon, G. E.; Leijtens, T.; Prasanna, R.; Habisreutinger, S. N.; Nemeth, W.; Gaulding, E. A.; Dunfield, S. P.; Reese, M.; Nanayakkara, S.; et al. Joule 2019, 3, 2193. doi: 10.1016/j.joule.2019.05.009

(49) Hu, M.; Bi, C.; Yuan, Y.; Bai, Y.; Huang, J. Adv. Science 2016, 3, 1500301. doi: 10.1002/advs.201500301

(50) Li, W.; Rothmann, M. U.; Liu, A.; Wang, Z.; Zhang, Y.; Pascoe, A. R.; Lu, J.; Jiang, L.; Chen, Y.; Huang, F.; et al. Adv. Energy Mater. 
2017, 7, 1700946. doi: 10.1002/aenm.201700946

(51) Braly, I. L.; Stoddard, R. J.; Rajagopal, A.; Uhl, A. R.; Katahara, J. K.; Jen, A. K. Y.; Hillhouse, H. W. ACS Energy Lett. 2017, 2, 1841 doi: 10.1021/acsenergylett.7b00525

(52) Kulbak, M.; Gupta, S.; Kedem, N.; Levine, I.; Bendikov, T.; Hodes, G.; Cahen, D. J. Phys. Chem. Lett. 2016, 7, 167. doi: 10.1021/acs.jpclett.5b02597

(53) Chen, C. Y.; Lin, H. Y.; Chiang, K. M.; Tsai, W. L.; Huang, Y. C.; Tsao, C. S.; Lin, H. W. Adv. Mater. 2017, 29, 1605290. doi: 10.1002/adma.201605290

(54) Lau, C. F. J.; Deng, X.; Ma, Q.; Zheng, J.; Yun, J. S.; Green, M. A.; Huang, S.; Ho-Baillie, A. W. Y. ACS Energy Lett. 2016, 1, 573. doi: 10.1021/acsenergylett.6b00341

(55) Liang, J.; Wang, C.; Wang, Y.; Xu, Z.; Lu, Z.; Ma, Y.; Zhu, H.; Hu, Y.; Xiao, C.; Yi, X.; et al. J. Am. Chem. Soc. 2016, 138, 15829. doi: $10.1021 /$ jacs.6b10227

(56) Wang, Y.; Dar, M. I.; Ono, L. K.; Zhang, T.; Kan, M.; Li, Y.; Zhang, L.; Wang, X.; Yang, Y.; Gao, X.; et al. Science 2019, 365, 591. doi: $10.1126 /$ science.aav8680

(57) Wang, Y.; Liu, X.; Zhang, T.; Wang, X.; Kan, M.; Shi, J.; Zhao, Y. Angew. Chem. Int. Ed. 2019, 58, 16691. doi: 10.1002/anie.201910800

(58) Wang, P.; Zhang, X.; Zhou, Y.; Jiang, Q.; Ye, Q.; Chu, Z.; Li, X.; Yang, X.; Yin, Z.; You, J. Nat. Commun. 2018, 9, 2225. doi: 10.1038/s41467-018-04636-4

(59) Stoumpos, C. C.; Kanatzidis, M. G. Acc. Chem. Res. 2015, 48, 2791. doi: 10.1021/acs.accounts.5b00229

(60) Goldschmidt, V. M. Naturwissenschaften 1926, 14, 477. doi: $10.1007 / \mathrm{BF} 01507527$

(61) Sutton, R. J.; Eperon, G. E.; Miranda, L.; Parrott, E. S.; Kamino, B. A.; Patel, J. B.; Hörantner, M. T.; Johnston, M. B.; Haghighirad, A. A.; Moore, D. T.; et al. Adv. Energy Mater. 2016, 6, 1502458. doi: 10.1002/aenm.201502458

(62) Chen, W.; Chen, H.; Xu, G.; Xue, R.; Wang, S.; Li, Y.; Li, Y. Joule 2019, 3, 191. doi: 10.1016/j.joule.2018.10.011

(63) Liu, C.; Li, W.; Zhang, C.; Ma, Y.; Fan, J.; Mai, Y. J. Am. Chem. Soc. 2018, 140, 3825. doi: $10.1021 /$ jacs.7b13229

(64) Tian, J.; Xue, Q.; Tang, X.; Chen, Y.; Li, N.; Hu, Z.; Shi, T.; Wang, X.; Huang, F.; Brabec, C. J.; et al. Adv. Mater. 2019, 31, 1901152. doi: 10.1002/adma.201901152

(65) Xiang, S.; Fu, Z.; Li, W.; Wei, Y.; Liu, J.; Liu, H.; Zhu, L.; Zhang, R.; Chen, H. ACS Energy Lett. 2018, 3, 1824. doi: 10.1021/acsenergylett.8b00820

(66) Zhao, B.; Jin, S. F.; Huang, S.; Liu, N.; Ma, J. Y.; Xue, D. J.; Han, Q.; Ding, J.; Ge, Q. Q.; Feng, Y.; et al. J. Am. Chem. Soc. 2018, 140, 11716. doi: $10.1021 /$ jacs.8b06050

(67) Ke, W.; Spanopoulos, I.; Stoumpos, C. C.; Kanatzidis, M. G. Nat.
Commun. 2018, 9, 4785. doi: 10.1038/s41467-018-07204-y

(68) Swarnkar, A.; Marshall, A. R.; Sanehira, E. M.; Chernomordik, B. D.; Moore, D. T.; Christians, J. A.; Chakrabarti, T.; Luther, J. M. Science 2016, 354, 92. doi: 10.1126/science.aag2700

(69) Ding, L. M.; Cheng, Y. B.; Tang, J. Acta Phys. -Chim. Sin. 2018, 34, 449. [丁黎明, 程一兵, 唐江. 物理化学学报, 2018, 34, 449.] doi: 10.3866/PKU.WHXB201710121

(70) Slavney, A. H.; Hu, T.; Lindenberg, A. M.; Karunadasa, H. I. J. Am. Chem. Soc. 2016, 138, 2138. doi: 10.1021/jacs.5b13294

(71) Saparov, B.; Hong, F.; Sun, J. P.; Duan, H. S.; Meng, W.; Cameron, S.; Hill, I. G.; Yan, Y.; Mitzi, D. B. Chem. Mater. 2015, 27, 5622. doi: 10.1021/acs.chemmater.5b01989

(72) Wu, C.; Zhang, Q.; Liu, Y.; Luo, W.; Guo, X.; Huang, Z.; Ting, H.; Sun, W.; Zhong, X.; Wei, S.; et al. Adv. Sci. 2018, 5, 1700759. doi: 10.1002/advs.201700759

(73) Zhao, D.; Yu, Y.; Wang, C.; Liao, W.; Shrestha, N.; Grice, C. R.; Cimaroli, A. J.; Guan, L.; Ellingson, R. J.; Zhu, K.; et al. Nat. Energy 2017, 2, 17018. doi: 10.1038/nenergy.2017.18

(74) Li, Z.; Zhao, Y.; Wang, X.; Sun, Y.; Zhao, Z.; Li, Y.; Zhou, H.; Chen, Q. Joule 2018, 2, 1559. doi: 10.1016/j.joule.2018.05.001

(75) Stoumpos, C. C.; Malliakas, C. D.; Kanatzidis, M. G. Inorg. Chem. 2013, 52, 9019. doi: $10.1021 /$ ic401215x

(76) Hao, F.; Stoumpos, C. C.; Chang, R. P. H.; Kanatzidis, M. G. J. Am. Chem. Soc. 2014, 136, 8094. doi: 10.1021/ja5033259

(77) Liao, W.; Zhao, D.; Yu, Y.; Shrestha, N.; Ghimire, K.; Grice, C. R.; Wang, C.; Xiao, Y.; Cimaroli, A. J.; Ellingson, R. J.; et al. J. Am. Chem. Soc. 2016, 138, 12360. doi: 10.1021/jacs.6b08337

(78) Klug, M. T.; Milot, R. L.; Patel, J. B.; Green, T.; Sansom, H. C.; Farrar, M. D.; Ramadan, A. J.; Martani, S.; Wang, Z.; Wenger, B.; et al. Energy Environ. Sci. 2020, 13, 1776. doi: 10.1039/D0EE00132E

(79) Chung, I.; Song, J. H.; Im, J.; Androulakis, J.; Malliakas, C. D.; Li, H.; Freeman, A. J.; Kenney, J. T.; Kanatzidis, M. G. J. Am. Chem. Soc. 2012, 134, 8579. doi: 10.1021/ja301539s

(80) Kumar, M. H.; Dharani, S.; Leong, W. L.; Boix, P. P.; Prabhakar, R. R.; Baikie, T.; Shi, C.; Ding, H.; Ramesh, R.; Asta, M.; et al. Adv. Mater. 2014, 26, 7122. doi: 10.1002/adma.201401991

(81) Jiang, T.; Chen, Z.; Chen, X.; Liu, T.; Chen, X.; Sha, W. E. I.; Zhu, H.; Yang, Y. Sol. RRL 2019, 4, 1900467. doi: 10.1002/solr.201900467

(82) Xu, X.; Chueh, C. C.; Yang, Z.; Rajagopal, A.; Xu, J.; Jo, S. B.; Jen, A. K. Y. Nano Energy 2017, 34, 392. doi: 10.1016/j.nanoen.2017.02.040

(83) Tai, Q.; Guo, X.; Tang, G.; You, P.; Ng, T. W.; Shen, D.; Cao, J.; Liu, C. K.; Wang, N.; Zhu, Y.; et al. Angew. Chem. Int. Ed. 2019, 58, 806. doi: 10.1002/anie.201811539

(84) He, X.; Wu, T.; Liu, X.; Wang, Y.; Meng, X.; Wu, J.; Noda, T.; Yang, X.; Moritomo, Y.; Segawa, H.; et al. J. Mater. Chem. A 2020, 8 , 
2760. doi: 10.1039/C9TA13159K

(85) Prasanna, R.; Leijtens, T.; Dunfield, S. P.; Raiford, J. A.; Wolf, E. J.; Swifter, S. A.; Werner, J.; Eperon, G. E.; de Paula, C.; Palmstrom, A. F.; et al. Nat. Energy 2019, 4, 939. doi: 10.1038/s41560-019-0471-6

(86) Liao, Y.; Liu, H.; Zhou, W.; Yang, D.; Shang, Y.; Shi, Z.; Li, B.; Jiang, X.; Zhang, L.; Quan, L. N.; et al. J. Am. Chem. Soc. 2017, 139, 6693. doi: 10.1021/jacs.7b01815

(87) Meng, L.; You, J.; Yang, Y. Nat. Commun. 2018, 9, 5265. doi: $10.1038 / \mathrm{s} 41467-018-07255-1$

(88) Christians, J. A.; Miranda Herrera, P. A.; Kamat, P. V. J. Am. Chem. Soc. 2015, 137, 1530. doi: 10.1021/ja511132a

(89) Niu, G.; Guo, X.; Wang, L. J. Mater. Chem. A 2015, 3, 8970. doi: $10.1039 /$ C4TA04994B

(90) Juarez-Perez, E. J.; Hawash, Z.; Raga, S. R.; Ono, L. K.; Qi, Y. Energy Environ. Sci. 2016, 9, 3406. doi: 10.1039/C6EE02016J

(91) Conings, B.; Drijkoningen, J.; Gauquelin, N.; Babayigit, A.; D'Haen, J.; D'Olieslaeger, L.; Ethirajan, A.; Verbeeck, J.; Manca, J.; Mosconi, E.; et al. Adv. Energy Mater. 2015, 5, 1500477. doi: 10.1002/aenm.201500477

(92) Misra, R. K.; Aharon, S.; Li, B.; Mogilyansky, D.; Visoly-Fisher, I.; Etgar, L.; Katz, E. A. J. Phys. Chem. Lett. 2015, 6, 326. doi: $10.1021 / \mathrm{jz} 502642 \mathrm{~b}$

(93) Turren-Cruz, S.-H.; Hagfeldt, A.; Saliba, M. Science 2018, 362, 449. doi: $10.1126 /$ science.aat 3583

(94) Bi, F.; Zheng, X.; Yam, Z. Acta Phys. -Chim. Sin. 2019, 35, 69. [毕富珍, 郑晓, 任志勇. 物理化学学报, 2019, 35, 69.] doi: 10.3866/PKU.WHXB201801082

(95) Lee, J. W.; Kim, D. H.; Kim, H. S.; Seo, S. W.; Cho, S. M.; Park, N. G. Adv. Energy Mater. 2015, 5, 1501310. doi: $10.1002 /$ aenm. 201501310

(96) Buin, A.; Pietsch, P.; Xu, J.; Voznyy, O.; Ip, A. H.; Comin, R.; Sargent, E. H. Nano Lett. 2014, 14, 6281. doi: 10.1021/n1502612m

(97) Yin, W. J.; Shi, T.; Yan, Y. Adv. Mater. 2014, 26, 4653. doi: 10.1002/adma.201306281

(98) Wetzelaer, G. J. A. H.; Scheepers, M.; Sempere, A. M.; Momblona, C.; Ávila, J.; Bolink, H. J. Adv. Mater. 2015, 27, 1837. doi: 10.1002/adma.201405372

(99) Fan, R.; Zhou, W.; Huang, Z.; Zhou, H. EnergyChem 2020, 2, 100032. doi: 10.1016/j.enchem.2020.100032

(100) Chen, Y.; Li, N.; Wang, L.; Li, L.; Xu, Z.; Jiao, H.; Liu, P.; Zhu, C.; Zai, H.; Sun, M.; et al. Nat. Commun. 2019, 10, 1112. doi: $10.1038 / \mathrm{s} 41467-019-09093-1$

(101) Wang, F.; Geng, W.; Zhou, Y.; Fang, H. H.; Tong, C. J.; Loi, M. A.; Liu, L. M.; Zhao, N. Adv. Mater. 2016, 28, 9986. doi: 10.1002/adma.201603062
(102) Calado, P.; Telford, A. M.; Bryant, D.; Li, X.; Nelson, J.; O'Regan, B. C.; Barnes, P. R. F. Nat. Commun. 2016, 7, 13831. doi: $10.1038 /$ ncomms 13831

(103) Shao, Y.; Fang, Y.; Li, T.; Wang, Q.; Dong, Q.; Deng, Y.; Yuan, Y.; Wei, H.; Wang, M.; Gruverman, A.; et al. Energy Environ. Sci. 2016, 9, 1752. doi: 10.1039/C6EE00413J

(104) Yuan, Y.; Huang, J. Acc. Chem. Res. 2016, 49, 286. doi: 10.1021/acs.accounts.5b00420

(105) Domanski, K.; Roose, B.; Matsui, T.; Saliba, M.; Turren-Cruz, S. H.; Correa-Baena, J. P.; Carmona, C. R.; Richardson, G.; Foster, J. M.; De Angelis, F.; et al. Energy Environ. Sci. 2017, 10, 604. doi: 10.1039/C6EE03352K

(106) Abdi-Jalebi, M.; Andaji-Garmaroudi, Z.; Cacovich, S.; Stavrakas, C.; Philippe, B.; Richter, J. M.; Alsari, M.; Booker, E. P.; Hutter, E. M.; Pearson, A. J.; et al. Nature 2018, 555, 497. doi: $10.1038 /$ nature 25989

(107) Li, N.; Tao, S.; Chen, Y.; Niu, X.; Onwudinanti, C. K.; Hu, C.; Qiu, Z.; Xu, Z.; Zheng, G.; Wang, L.; et al. Nat. Energy 2019, 4, 408. doi: 10.1038/s41560-019-0382-6

(108) Wang, L.; Zhou, H.; Hu, J.; Huang, B.; Sun, M.; Dong, B.; Zheng, G.; Huang, Y.; Chen, Y.; Li, L.; et al. Science 2019, 363, 265. doi: 10.1126/science.aau5701

(109) Lin, Y.; Bai, Y.; Fang, Y.; Wang, Q.; Deng, Y.; Huang, J. ACS Energy Lett. 2017, 2, 1571. doi: 10.1021/acsenergylett.7b00442

(110) Lee, J. W.; Dai, Z.; Han, T. H.; Choi, C.; Chang, S. Y.; Lee, S. J.; De Marco, N.; Zhao, H.; Sun, P.; Huang, Y.; et al. Nat. Commun. 2018, 9, 3021. doi: 10.1038/s41467-018-05454-4

(111) Liu, Y.; Yang, Z.; Cui, D.; Ren, X.; Sun, J.; Liu, X.; Zhang, J.; Wei, Q.; Fan, H.; Yu, F.; et al. Adv. Mater. 2015, 27, 5176. doi: 10.1002/adma.201502597

(112) Xie, F.; Chen, C. C.; Wu, Y.; Li, X.; Cai, M.; Liu, X.; Yang, X.; Han, L. Energy Environ. Sci. 2017, 10, 1942. doi: 10.1039/C7EE01675A

(113) Yu, H.; Wang, F.; Xie, F.; Li, W.; Chen, J.; Zhao, N. Adv. Funct. Mater. 2014, 24, 7102. doi: 10.1002/adfm.201401872

(114) Liu, J.; Gao, C.; He, X.; Ye, Q.; Ouyang, L.; Zhuang, D.; Liao, C.; Mei, J.; Lau, W. ACS Appl. Mater. Interfaces 2015, 7, 24008. doi: 10.1021/acsami.5b06780

(115) Zhou, H.; Chen, Q.; Li, G.; Luo, S.; Song, T. B.; Duan, H. S.; Hong, Z.; You, J.; Liu, Y.; Yang, Y. Science 2014, 345, 542. doi: 10.1126/science. 1254050

(116) Xiao, Z.; Dong, Q.; Bi, C.; Shao, Y.; Yuan, Y.; Huang, J. Adv. Mater. 2014, 26, 6503. doi: 10.1002/adma.201401685

(117) Jain, S. M.; Qiu, Z.; Häggman, L.; Mirmohades, M.; Johansson, M. B.; Edvinsson, T.; Boschloo, G. Energy Environ. Sci. 2016, 9, 3770. doi: 10.1039/C6EE02544G 
(118) Xiao, S.; Bai, Y.; Meng, X.; Zhang, T.; Chen, H.; Zheng, X.; Hu, C.; Qu, Y.; Yang, S. Adv. Funct. Mater. 2017, 27, 1604944.

doi: 10.1002/adfm.201604944

(119) Bush, K. A.; Bailie, C. D.; Chen, Y.; Bowring, A. R.; Wang, W.; Ma, W.; Leijtens, T.; Moghadam, F.; McGehee, M. D. Adv. Mater. 2016, 28, 3937. doi: 10.1002/adma.201505279

(120) Löper, P.; Moon, S. J.; Martín de Nicolas, S.; Niesen, B.; Ledinsky, M.; Nicolay, S.; Bailat, J.; Yum, J. H.; De Wolf, S.; Ballif, C. Phys. Chem. Chem. Phys. 2015, 17, 1619. doi: 10.1039/C4CP03788J

(121) Chang, C. Y.; Tsai, B. C.; Hsiao, Y. C.; Lin, M. Z.; Meng, H. F.
Nano Energy 2019, 55, 354. doi: 10.1016/j.nanoen.2018.10.014

(122) Jiang, F.; Liu, T.; Luo, B.; Tong, J.; Qin, F.; Xiong, S.; Li, Z.; Zhou, Y. J. Mater. Chem. A 2016, 4, 1208. doi: 10.1039/C5TA08744A

(123) Yeo, J. S.; Kang, R.; Lee, S.; Jeon, Y. J.; Myoung, N.; Lee, C. L.; Kim, D. Y.; Yun, J. M.; Seo, Y. H.; Kim, S. S.; et al. Nano Energy 2015, 12, 96. doi: 10.1016/j.nanoen.2014.12.022

(124) Khenkin, M. V.; Katz, E. A.; Abate, A.; Bardizza, G.; Berry, J. J.; Brabec, C.; Brunetti, F.; Bulović, V.; Burlingame, Q.; Di Carlo, A.; et al. Nat. Energy 2020, 5, 35. doi: 10.1038/s41560-019-0529-5 